\title{
LA CONSTITUCIONALIZACIÓN DEL GOBIERNO JUDICIAL: CUARENTA AÑOS DE CONSEJO GENERAL DEL PODER JUDICIAL, RÉGIMEN ACTUAL Y CUESTIONES PENDIENTES
}

GEMA ROSADO IGLESIAS 
SUMARIO

I. LA CONSTITUCIONALIZACIÓN DEL GOBIERNO JUDICIAL: CUARENTA AÑOS DE CONSEJO GENERAL DEL PODER JUDICIAL. II. RÉGIMEN ACTUAL Y CUESTIONES PENDIENTES. 1. En general sobre la Ley Orgánica 4/2013, de reforma del Consejo General del Poder Judicial. 2. Sistema de elección, estatuto de los vocales y renovación del órgano. 3. Estructura orgánica del Consejo General del Poder Judicial y cuestiones relativas al funcionamiento de los órganos. 4. Atribuciones del Consejo General del Poder Judicial. 5. Relaciones entre el Consejo General del Poder Judicial y las Cortes Generales: las comparecencias del Presidente y de los vocales ante las Cámaras parlamentarias. III. CONSIDERACIONES FINALES 


\title{
LA CONSTITUCIONALIZACIÓN DEL GOBIERNO JUDICIAL: CUARENTA AÑOS DE CONSEJO GENERAL DEL PODER JUDICIAL, RÉGIMEN ACTUAL Y CUESTIONES PENDIENTES
}

\author{
GEMA ROSADO IGLESIAS ${ }^{1}$ \\ Derecho Constitucional \\ Universidad Carlos III de Madrid
}

\section{LA CONSTITUCIONALIZACIÓN DEL GOBIERNO JUDICIAL: CUARENTA AÑOS DE CONSEJO GENERAL DEL PODER JUDICIAL}

Con el art. 122, párrafos 2 y 3, la Constitución española de 1978 incorpora nuestro ordenamiento constitucional al modelo creado por los textos constitucionales francés e italiano que surgieron en la segunda posguerra y que perseguían con la creación del Conseil Superieur de la Magistrature y el Consiglio Superiore della Magistratura, respectivamente, sustraer de la órbita del poder ejecutivo, concretamente, del ámbito competencial del Ministerio de Justicia, aquellas atribuciones de organización y gestión del Poder Judicial que, potencialmente, podían ser utilizadas políticamente, bien como recompensas, bien como correctivos en función de la posición y decisiones adoptadas por jueces y magistrados. La creación de instituciones de esta naturaleza pretendía reforzar las garantías de la independencia judicial en el ejercicio de la función jurisdiccional, entregando a estos órganos el ejercicio de determinadas funciones estrechamente conectadas con el estatuto judicial.

En este contexto, con el referente de los dos modelos citados, si bien con mayor influencia del italiano, la Constitución de 1978 da a luz a un nuevo órgano al que se denomina Consejo General del Poder Judicial (en adelante, CGPJ, o el Consejo), cuya regulación y desarrollo normativo se encomienda a la Ley Orgánica, y al que se atri-

${ }^{1}$ Profesora Titular de Derecho Constitucional. Universidad Carlos III de Madrid. Facultad de Ciencias Sociales y Jurídicas. Departamento de Derecho Público del Estado. C/ Madrid, 126. 28903 Getafe. Email: grosado@der-pu.uc3m.es 
buyen un catálogo de funciones básicas, a saber, «en particular en materia de nombramientos, inspección y régimen disciplinario.»

Poco más añade el texto constitucional, salvo la determinación de la composición del órgano: veinte miembros nombrados por el Rey, para un periodo de cinco años, de los que doce han de ser designados entre jueces y magistrados y los ocho restantes entre abogados y juristas de reconocida competencia y con más de quince años de ejercicio profesional, y un Presidente, elegido por éstos, que actuará además como Presidente del Tribunal Supremo.

Tampoco el procedimiento de selección y designación de los miembros de este órgano se recoge con detalle en el texto constitucional, más allá de disponer que se realizará conforme a los términos que establezca la Ley Orgánica, y que, en todo caso, puesto que esto sí se impone constitucionalmente, cuatro lo serán a propuesta del Congreso y cuatro a propuesta del Senado, elegidos en ambos casos por mayoría de tres quintos de los miembros de cada Cámara.

Esta ambigüedad e indeterminación constitucional será la causa de la primera gran polémica que ha debido afrontar el Consejo, polémica que no sólo no ha mermado con el tiempo, sino que, cuarenta años después, pervive en el tiempo y se reaviva con cada nueva reforma de la Ley Orgánica del Poder Judicial (en adelante, LOPJ), y del CGPJ.

Con cierta premura, en tanto el proceso de constitución del Tribunal Constitucional precisaba de la previa constitución del CGPJ, al que el art. 159.1 CE atribuye la propuesta de dos miembros para el Tribunal, se aprobó la Ley Orgánica 1/1980, de 10 de enero, reguladora del Consejo General del Poder Judicial. La mencionada Ley optaba por un procedimiento de elección de los miembros del Consejo que bien puede considerarse como el que más naturalmente se infiere del texto constitucional: nombramiento parlamentario con mayoría cualificada de los miembros no judiciales, los juristas, como recoge explícitamente el art. 122.3 CE, y selección y elección de los miembros judiciales, jueces y magistrados de todas las categorías judiciales en el decir constitucional, por medio de un sistema de elecciones internas entre los propios jueces y magistrados en activo.

El régimen de elección establecido para los vocales judiciales en la Ley Orgánica de 1980 preveía además que la propuesta debía comprender tres magistrados del Tribunal Supremo, seis magistrados y tres jueces, que las candidaturas, que habrían de contar con el aval de un diez por ciento de los electores o de una asociación profesional válidamente constituida, eran abiertas, de forma que el elector podía combinar los nombres, dentro de una misma categoría, correspondientes a diferentes candidaturas y que el sistema electoral fuese el mayoritario corregido.

La experiencia de este modelo puso de manifiesto que, a pesar de la pretensión legal de permitir la representación del sector minoritario, el sistema arbitrado, combinado con la previsión de una circunscripción única para todo el territorio nacional, favorecía claramente al sector mayoritario, dominante, conservador, en el estamento judicial que copó todos los puestos. 
Como respuesta a esta falta de representación del sector minoritario, Congreso y Senado dieron entrada entre los juristas de reconocido prestigio que debían designar a miembros de la carrera judiciales alineados con otras corrientes ideológicas, iniciándose así una práctica que no parece que se compadezca bien con los términos y fines constitucionales, y que se ha mantenido en Consejos posteriores, y que incluso hoy, tras la reforma operada por la Ley Orgánica 4/2013, parece haber tenido acogida en el texto legal (sobre ello se volverá más adelante).

El CGPJ, que comenzó a actuar en octubre de 1980, contaba en esta coyuntura con una sobrerrepresentación de vocales judiciales, que debió llevarle a concebirse y autoproclamarse como órgano de autogobierno del Poder Judicial, a reclamar un aumento de sus competencias, y a potenciar en lo posible su posición institucional, para venir a situarse en el mismo plano en la estructura de división de poderes que los poderes propiamente políticos, Cámaras parlamentarias y Gobierno. Su actuación, la reivindicación de una ampliación de competencias en materias de contenido político, y su composición no le mostraron, de principio, como un órgano apto para adaptar el modelo judicial heredado del franquismo al nuevo papel y las misiones que la Constitución le reservaba.

Seguramente estas circunstancias condicionaron la primera gran reforma del Consejo en lo relativo al proceso de selección y elección de los miembros judiciales del CGPJ. Con la Ley Orgánica 6/1985, del Poder Judicial, el legislador dio entrada a un modelo radicalmente distinto en esta materia, que, con modificaciones puntuales, permanece en su aspecto trascendental: la designación parlamentaria de todos los miembros del Consejo, judiciales y juristas.

En la Ley Orgánica 6/1985, todos los vocales pasaron a ser seleccionados por las Cámaras parlamentarias, si bien doce habrían de ser designados entre jueces y magistrados de todas las categorías judiciales, eligiéndose, como los ocho restantes, la mitad por cada Cámara por una mayoría de tres quintos (art. 112 LOPJ, en la redacción entonces vigente).

El nuevo modelo, además de una tramitación parlamentaria caracterizada por diferentes vicisitudes ${ }^{2}$, no tuvo una acogida favorable en los sectores judiciales. De hecho el Consejo, que desde que comenzó su andadura se autoatribuyó la función de representar al Poder Judicial y a sus miembros ante los demás poderes y órganos del Estado, y entendió que la Constitución creaba un órgano de autogobierno judicial, que no establece, promovió conflicto de competencias entre órganos constitucionales frente a este nuevo modelo. Por su parte, el Partido Popular también acudió al Tri-

2 De las que la más llamativa y conocida seguramente sea el modo en que se introdujo el modelo. En el Proyecto de Ley Orgánica presentado por el Gobierno, sustentado por el Partido Socialista, se mantenía el sistema anterior de elección, la introducción del cambio en la elección se produjo a través de la aceptación por el Grupo Socialista, en el debate en el seno de la Comisión de Justicia del Congreso, de la enmienda presentada por el diputado José María Bandrés que contemplaba que la elección de todos los miembros del Consejo fueran nombrados por las Cámaras parlamentarias por la mayoría reforzada de tres quintos. 
bunal Constitucional, interponiendo recurso de inconstitucionalidad contra la Ley Orgánica mencionada. Ambos procedimientos fueron desestimados por el Tribunal en las Sentencias 45/1986 y 108/1986, respectivamente.

No obstante, junto a estas declaraciones de constitucionalidad, especialmente en la dictada en la Sentencia 108/1986, el Tribunal planteó algunas dudas sobre el modelo elegido y alertó del riesgo de dejar entrar en el proceso de designación de los miembros del Consejo el juego político, y de que la posición del órgano quedara comprometida y su actuación pervertida.

Aceptando el Tribunal que la remisión contenida en el art. 122.2 CE en favor de la Ley Orgánica permite diferentes interpretaciones, entre la se encuentran tanto la opción adoptada por la Ley de 1980 como la reforma posterior de 1985, que cumple actualizar al legislador al que la Constitución reconoce un amplio margen de discrecionalidad, aconseja, con todo, su sustitución, avisa sobre el riesgo antedicho, y subraya que el límite que en todo caso no puede superar el legislador al regular el Consejo es el respeto al lugar asignado a este órgano por la Constitución, de forma que ocupe una posición autónoma y no subordinada al resto de los poderes públicos ${ }^{3}$.

El resultado práctico del modelo pronto hizo patente la realidad de los recelos del Tribunal. De hecho, la permanente aplicación de los Grupos Parlamentarios de la práctica de cuotas en el reparto y elección de los miembros del Consejos, y la selección de éstos conforme a criterios ideológicos, que ha marcado la política de designación de los vocales hasta hoy, ha lastrado el papel, la posición y la propia legitimidad del órgano. A ello tampoco ha sido ajeno el propio Consejo que, en su actividad y en sus actuaciones, da cuenta de las fuertes tensiones que existen en su seno entre los distintos sectores ideológicos, que los acuerdos se adoptan más por la pertenencia a uno de dichos bloques que por criterios jurídicos, lo que es especialmente patente en los nombramientos de cargos judiciales discrecionales, sin olvidar los escándalos que en demasiadas ocasiones han salpicado su actuación y de los que han dado cumplida cuenta los medios de comunicación, la asunción de funciones que no se corresponden con su función y posición constitucional, y el escaso peso que en su actuación ha tenido la garantía de la independencia de jueces y magistrados, cuando esta es su función constitucional primordial.

Lo cierto es que las posteriores reformas de la LOPJ no han servido para atajar estos inconvenientes y redefinir la posición constitucional del Consejo (tampoco la actualmente vigente como luego se verá), de forma que este órgano sometido a un permanente y constante proceso de reforma cada vez es más cuestionado, incluso hay

${ }^{3}$ Con rotundidad lo afirmará en el fundamento jurídico 8 de la Sentencia al decir que «lo único que resulta de la regulación (constitucional) es que se ba querido crear un órgano autónomo que desempeñe determinadas funciones, cuya asunción por el Gobierno podría enturbiar la imagen de la independencia judicial, pero sin que de ello se derive que ese órgano sea expresión del autogobierno de los Jueces», y que "la verdadera garantía de que el Consejo cumpla el papel que le ha sido asignado por la Constitución en defensa de la independencia judicial no consiste en que sea el órgano de autogobierno de los Jueces sino en que ocupe una posición autónoma y no subordinada a los demás poderes públicos». Fundamento jurídico 10 de la Sentencia 108/1986. 
quien pide su supresión de plano (lo que, en buena lógica, crearía nuevos problemas, para empezar ¿quién asumiría sus funciones?, ¿el Ministerio de Justicia?, no parece lo más adecuado toda vez las razones que llevaron a su constitucionalización), y que parece cada vez más alejado de su posición constitucional.

Pero volviendo a las modificaciones de la LOPJ, la Ley Orgánica 2/2001, de 28 de junio, sobre la composición del Consejo General del Poder Judicial, opta por un modelo mixto, de forma que los vocales judiciales, cuya propuesta correspondería a las Cámaras legislativas, se elegirían por ellas de entre los treinta y seis candidatos presentados por jueces y magistrados. El cambio no fue en la práctica trascendental, manteniéndose los inconvenientes del sistema de 1985, el reparto de puestos y designación por cuotas y la elección conforme a criterios ideológicos, y los de 1980, la sobrerrepresentación de las asociaciones judiciales mayoritarias (Asociación Profesional de la Magistratura y Jueces para la Democracia), con la escasa entrada de algún vocal perteneciente a las que tienen menos afiliados (Francisco de Vitoria y Foro Judicial Independiente), y la prácticamente nula representación de los jueces no asociados, aunque vienen constituyendo la mitad de los miembros en activo de la carrera judicial.

La siguiente reforma en esta materia ha sido la realizada por la Ley Orgánica $4 / 2013$, actualmente vigente, y a la que se dedicará el núcleo de este estudio por lo que no la trataremos ahora.

En cuanto a las atribuciones del Consejo también han sido objeto de modificación. Si bien es cierto que la materia no ha despertado tanta polémica como los aspectos referentes al sistema de selección y elección de los vocales judiciales, han sido precisamente las funciones menos conectadas con la función constitucional del CGPJ, las encomendadas no por el texto constitucional sino por la Ley Orgánica correspondiente, las que han generado mayor controversia, como es el caso de la potestad reglamentaria del Consejo y singularmente su extensión y alcance, o la competencia consultiva, la emisión de informes, habitualmente ejercida más allá incluso de los términos legales y con un objetivo claro de influencia política y desde posicionamientos marcadamente político-ideológicos, o las competencias en materia internacional, o en la gestión de la estadística judicial.

La Ley Orgánica 1/1980, con una concepción amplia de qué sea el gobierno del Poder Judicial, dotó al Consejo de un generoso listado de competencias, incrementando, así, el elenco estricto e irreductible de atribuciones que la Constitución encomienda a este órgano ${ }^{4}$. Por su parte, la LOPJ de 1985, ante las demandas constantes del órgano, en su primera composición, de un incremento de sus competencias, y su actuación en tal sentido, introdujo una regulación más sistemática y detallista, manteniendo prácticamente el status quo, sin alteración sustancial de

${ }^{4}$ En detalle sobre la exposición de estas atribuciones Luis AguiAR De LuQue: «Continuidad y reforma en el Régimen Jurídico del Consejo General del Poder Judicial», en Luis Aguiar DE LuQuE: Independencia Judicial y Estado Constitucional. El gobierno judicial, Valencia, Tirant lo Blanch, 2016, págs. 20 y sigs. 
la posición y el papel de la institución, aunque sí intentó reconducir el potencial institucional del órgano, retirando alguna de las competencias atribuidas al CGPJ en la Ley anterior. En este sentido, la LOPJ de 1985 suprime del ámbito competencial del Consejo lo relativo a Secretarios Judiciales y demás personal al servicio de la Administración de Justicia, intenta delimitar de forma más adecuada los contornos de la potestad reglamentaria del órgano, y amplía el ámbito de la potestad de informe sobre proyectos de ley.

Pero, si bien es cierto que esta extensión de la facultad consultiva del Consejo no aventuraba por sí misma, en el momento de aprobación de la Ley, la utilización excesiva y abusiva que el CGPJ habría de darle, la potestad reglamentaria, su extensión y alcance habían sido ya con la Ley Orgánica 1/1980 foco de discusión, que se potenciará con la aprobación en 1985 de la LOPJ y su regulación más contenida de esta competencia que queda, en el texto de la Ley (art. 110 LOPJ de 1985), circunscrita a la potestad normativa doméstica, interna, eliminando del precepto legal el inciso recogido en la redacción anterior sobre el que sustentaba la defensa de una cierta extensión hacia la potestad reglamentaria ad extra del CGPJ.

Esta limitación fue objeto de recurso de inconstitucionalidad, por entender, los cincuenta y cinco diputados promotores del recurso, que se trataba de una exclusión ilegítima de la competencia reglamentaria ad extra del órgano en beneficio del gobierno al que la Disposición adicional primera atribuía la potestad de dictar los reglamentos que exigiera el desarrollo de la LOPJ. Pues bien, aunque el Tribunal, en la Sentencia 108/1986, rechaza los argumentos concretos utilizados por los recurrentes, indirectamente da una respuesta favorable a su pretensión: pese a no declarar la inconstitucionalidad del precepto legal impugnado, la mencionada Disposición adicional primera, el Tribunal sostendrá que los jueces y magistrados no pueden estar sometidos, como titulares de la potestad jurisdiccional, a normas de rango inferior a la ley y especialmente a los reglamentos del gobierno, pero tampoco en relación con su propio estatuto, pues «lo contrario supondría la posibilidad de influir en su situación personal con los riesgos que ello acarrea respecto a la misma función jurisdiccional» ${ }^{5}$. Con posterioridad la reforma de las atribuciones del Consejo no ha marcado la agenda legislativa del ejecutivo, sin perjuicio de puntuales modificaciones parciales «sin particular relevancia cada una de ellas individualmente consideradas, pero que insensiblemente han terminado por cambiar el papel del organismo» ${ }^{6}$ : singularmente las referidas en la Ley Orgánica 16/1994, de reforma de la LOPJ, o la participación en el régimen retributivo de jueces y magistrados que recoge la Ley Orgánica 15/2003; leyes que,

${ }^{5}$ Declaración que permite al Tribunal admitir la posibilidad de que el Consejo pueda dictar normas reglamentarias que afecten al estatuto de jueces y magistrados siempre que tengan carácter secundario y auxiliar, y no incidan en el conjunto de derechos y deberes configuradores del estatuto judicial, sino que se limiten a regular condiciones accesorias para su ejercicio. Fundamento jurídico 26 de la Sentencia $108 / 1986$.

6 Aguiar de Luque: «Continuidad y reforma en el Régimen Jurídico del Consejo General del Poder Judicial», cit., pág. 23. 
más allá de otras modificaciones puntuales, afectaron nuevamente a la delimitación de la potestad reglamentaria ad extra del CGPJ.

En primer lugar, la Ley Orgánica 16/1994 pretenderá actualizar la redacción del art. 110 LOPJ conforme a la interpretación de la Sentencia 108/1986 y del ejercicio de la misma realizado por el Consejo, ampliando la potestad reglamentaria del órgano, que podrá dictar reglamentos relativos al estatuto de jueces y magistrados, siempre que se encuentren en su ámbito de competencias, y pretendan un desarrollo de la LOPJ referido a regulaciones de carácter secundario y auxiliar, que sólo tengan como finalidad regular condiciones accesorias para el ejercicio de los derechos y deberes que conforman el estatuto judicial, sin innovar aquéllos ni alterar éste en su conjunto, y en especial, en una serie de materias que enumera, hasta un total de dieciocho.

La reforma de 1994 fue recurrida en inconstitucionalidad por el Partido Popular que reclamaba más potestad reglamentaria para el Consejo. El Tribunal, que resolvió el recurso en la Sentencia 105/2000, recordó que la facultad de regular las condiciones accesorias para el ejercicio de los derechos y deberes de jueces y magistrados pertenece en exclusiva al Consejo, no aplicándose las cláusulas subrogatorias cuando el legislador atribuya determinadas competencias al Consejo, y que fuera del ámbito de atribuciones que la Constitución reserva al CGPJ, nada impide al legislador atribuir indistintamente al gobierno o al Consejo competencias en el resto de materias ${ }^{7}$.

Por su parte la Ley Orgánica 15/2003 contiene una modificación de menor entidad en materia reglamentaria. En realidad, se limita a añadir una nueva materia a la potestad reglamentaria del Consejo recogida en el entonces vigente art. 110.2 LOPJ, relativo a los sistemas de racionalización, organización y medición del trabajo que se estimen convenientes con los que determinar la carga de trabajo que puede soportar un órgano jurisdiccional, así como establecer criterios mínimos homogéneos para la elaboración de normas de reparto.

Por lo demás, las competencias encomendadas al Consejo se han mantenido hasta la reforma realizada por la Ley Orgánica 4/2013, que constituye la legislación aplicable vigente y actual y a la que se dedicarán las páginas que siguen.

Pues bien, en este contexto normativo previo a la Ley Orgánica 4/2013, y aunque no cabe advertir una intención deliberada del legislador para ampliar las competencias del Consejo de forma sustancial, la práctica del órgano se puede decir que ha desbordado los términos legales, por la vía de una interpretación extensiva de sus competencias legales, y una política de comunicación del órgano de gobierno del Poder Judicial que le han convertido en protagonista y justificado su opinión ante cualquier asunto de la agenda pública, incluso en ocasiones cuando no se trataba de cuestiones directamente vinculadas con la actuación de Juzgados y Tribunales, y cuya decisión corresponde al legislador. A este protagonismo del Consejo y su asunción de una

${ }^{7}$ La Sentencia cuenta con un voto particular de Mendizábal al que se adhiere Jiménez de Parga, y otro de Conde Martín de Hijas. Ambos coinciden en entender que cualquier potestad reglamentaria en materia judicial debe corresponder al CGPJ, y que todo lo que sea atribuir a un órgano distinto del Consejo la regulación de cualquier ámbito institucional del Poder Judicial contraría la Constitución. 
pretendida función de indirizzo político, que la Constitución no le reconoce, también se ha contribuido desde las instituciones centrales del Estado favorable a potenciar la posición del Consejo reconociendo su papel en todo lo relativo a la Administración de Justicia, habida cuenta la doctrina sentada por el Tribunal Constitucional en relación con las cláusulas subrogatorias (Sentencias 56 y 62 de 1990) ${ }^{8}$, que permitía, al situar determinadas competencias en la órbita del Consejo, sustraer tales competencias de una eventual asunción competencial por las Comunidades Autónomas.

Lo antedicho ha tenido como consecuencia, como señala Aguiar ${ }^{9}$, que «el CGPJ ha terminado por convertirse en un órgano apetecido por los grupos parlamentaros en el momento de proveer al nombramiento de sus miembros como medio de ocupar espacios en el terreno institucional, pero que luego, en su funcionamiento cotidiano, ba funcionado habitualmente con amplias tensiones entre sus miembros y, en la práctica, ha operado a modo de "verso suelto" en el panorama del sistema de organización de poderes diseñado por el constituyente de 1978».

\section{RÉGIMEN JURÍDICO Y CUESTIONES PENDIENTES}

\section{En general sobre la Ley Orgánica 4/2013, de reforma del Consejo General del Poder Judicial}

La Ley Orgánica 4/2013, constituye la última reforma del órgano de gobierno del Poder Judicial previsto en el art. 122 del texto constitucional ${ }^{10}$; una reforma que, mediante un único artículo, introduce un nuevo Libro VIII a la Ley Orgánica del Poder Judicial dedicado a la regulación del Consejo General del Poder Judicial, que vino a sustituir, al derogar, la regulación contenida en el extinto Título II del Libro II de la LOPJ ${ }^{11}$, y que consolida el proceso de continua reforma que ha presidido la

${ }^{8}$ Con posterioridad se han dictado por el Tribunal Constitucional otras sentencias relativas a aspectos concretos de la Administración de Justicia (Sentencias 235/2005, 270/2006 y 294/2006). En las Sentencias 31 y 137/2010 se resuelven los recursos de inconstitucionalidad interpuestos por parlamentarios del Grupo Popular y por el Defensor del Pueblo. En el año 2012 pueden citarse las Sentencias 37/2012, y 163 y 224/2012, que resuelven los recursos de inconstitucionalidad plateados por el Parlamento y la Generalitat de Catalunya respecto a determinados preceptos de la Ley Orgánica 19/2003, y la Sentencia 238/2012 que resuelve el recurso promovido por el Grupo Popular contra la Ley Orgánica 2/2004 de reforma de la LOPJ. Al respecto, Gema Rosado Iglesias: «Gobierno del Poder Judicial y Estado autonómico», en Gerpe LANdín y CABEllos EsPiÉrRez: El Gobierno del Poder Judicial en el Estado autonómico. Evolución y perspectivas de reforma. Madrid, Marcial Pons, 2013, págs. 107 y sigs.

${ }^{9}$ Luis Aguiar de Luque: «El gobierno judicial en el derecho comparado: entre la dirección política y la gestión administrativa», en Luis Aguiar de Luque (dir.): El gobierno del poder judicial. Una perspectiva comparada. Centro de Estudios Políticos y Constitucionales, Madrid, 2012, pág. 17.

10 En realidad, la última modificación del Consejo General del Poder Judicial tuvo lugar como consecuencia de la aprobación de la Ley Orgánica 7/2015, que eleva el número de miembros de la Comisión Permanente del órgano de gobierno de 5 a 7 , más el Presidente.

11 Además, la LO 4/2013 preveía la derogación de La Ley Orgánica 1/2013, de 11 de abril, sobre el proceso de renovación del Consejo General del Poder Judicial, por la que se suspende la vigencia del artículo 112 y parcialmente del 114 de la Ley Orgánica 6/1985, de 1 de julio, del Poder Judicial. 
trayectoria de un órgano que no sólo no parece dar con un modelo adecuado para el cumplimiento de las pretensiones y expectativas de garantía de la independencia del Poder judicial frente al ejecutivo que sirvieron y guiaron su constitucionalización, sino que además es siempre cuestionado tanto por la regulación legislativa del mismo, como por la práctica y la actuación del propio órgano de gobierno ${ }^{12}$.

La referida Ley Orgánica 4/2013, que tiene su origen, casi remoto se podría decir habida cuenta de las modificaciones sustanciales que se introdujeron en el Anteproyecto y luego Proyecto de Ley Orgánica que se remitió al Congreso de los Diputados, en el borrador elaborado por la Comisión de juristas, la Comisión institucional creada por Acuerdo del Consejo de Ministros de marzo de 2012, según reza su Exposición de Motivos, aunque nace con la vocación de dar respuesta a la necesidad de una reforma, ha merecido una crítica casi unánime de la doctrina, bien por considerar que se ha vulnerado el espíritu y base constitucional ${ }^{13}$, bien por entender que no resuelve los problemas persistentes del modelo, incluso los agrava, o crea otros nuevos, en una suerte de permanente respuesta revanchista a la actuación del $\mathrm{CGPJ}^{14}$, y de huida hacia delante que lleva a algunos autores a pensar en la necesidad de una modificación constitucional del órgano, cuando no a su directa supresión ${ }^{15}$.

Las modificaciones introducidas por la Ley 4/2013 se refieren a los siguientes aspectos principales:

a) En cuanto al proceso de selección de los vocales de origen judicial, la Ley de reforma pretende promover la participación de los miembros de la carrera judicial reduciendo el número de avales necesario para presentar candidaturas, y da un mayor protagonismo a en este proceso de presentación de candidaturas a jueces y magistrados, toda vez que las asociaciones judiciales pueden avalar candidatos pero no pueden presentar candidaturas directamente.

Al mismo tiempo introduce una previsión (art. 589.2 y 3) relativa a la proporción entre vocales asociados y no asociados para que las Cortes Generales designen a los vocales de origen judicial, y establece proporciones relativas al origen, la categoría y antigüedad de los vocales judiciales. Disposiciones que, de un lado, no garantizan la adecuada proporcionalidad entre jueces y magistrados afiliados y no afiliados a cada una de las distintas asociaciones judiciales (no debe olvidarse que prácticamente la mitad de jueces y magistrados en activo no están asociados a ninguna de las asocia-

12 Elocuente es en este sentido ya el propio título del trabajo de GERPE LANDín, MANuEL y CABELlos Espiérrez, Miguel ANGel: «La reforma permanente: El Consejo General del Poder Judicial a la búsqueda de un modelo», Revista Española de Derecho Constitucional, núm. 103, 2015, págs. 13-44.

13 Gerpe Landín y Cabellos Espiérrez: «La reforma permanente...», cit., pág. 15.

${ }^{14}$ En este sentido, Diego Íñiguez Hernández: «La reforma del Consejo General del Poder Judicial en España. Noticia de otra reforma fallida», Cuadernos Manuel Giménez Abad, núm. 7, 2014, pág. 149.

15 Javier Tajadura Tejada: «La reforma del Consejo General del Poder Judicial», Diariovasco. com, 6 de febrero de 2012. José Eugenio Soriano García: El poder, la Administración y los jueces (A propósito de los nombramientos por el Consejo General del Poder Judicial). Madrid, Iustel, 2012. 
ciones judiciales), y, de otro, provoca lo que bien puede ser valorado como una representación desproporcionada en favor de los magistrados del Tribunal Supremo en relación con el resto de miembros de la carrera judicial, atendiendo al número existentes de unos y otros ${ }^{16}$.

b) Por lo que se refiere a la estructura orgánica del órgano, se configura una Comisión Permanente como verdadero órgano central y nuclear del Consejo, de su funcionamiento y decisiones, en detrimento del Pleno que queda relegado a funciones más residuales.

Además, reformula la estructura de las comisiones, y modifica sustancialmente la Comisión disciplinaria que quedará constituida por siete miembros, que no variaran durante los cinco años de mandato del Consejo, pero para los que, a diferencia de los miembros de la Comisión Permanente, no se dispone su exclusividad, sino que compatibilizarán su cargo con la función que vinieran ejerciendo hasta el momento.

Se crea la figura del Promotor de la Acción Disciplinaria, que queda vinculado y supeditado en ciertos casos a la Comisión Permanente, y se reformula la Vicepresidencia del CGPJ, introduciendo un Vicepresidente que suple en los casos previstos por la Ley al Presidente pero que no es miembro del CGPJ.

c) El estatuto de los vocales queda alterado, al establecerse el desempeño a tiempo parcial del cargo, salvo para los miembros de la Comisión Permanente y del Presidente que se dedicarán en exclusividad. Paralelamente, se prevé que se procurará la renovación anual de los miembros de la Comisión Permanente con la finalidad de que todos los miembros del CGPJ, salvo los de la Comisión disciplinaria que, como se ha dicho, permanecerán en el cargo durante los cinco años de mandato, formen parte en algún momento de la Comisión Permanente.

d) Con la intención de evitar las posibles situaciones de bloqueo en la constitución del órgano cuando las Cámaras, o, más precisamente, una de ellas no alcancen el acuerdo necesario para proceder a la designación de nuevos vocales, y evitar las prórrogatio en funciones que se han vuelto casi habituales en los procesos de renovación del CGPJ, se establece que el nuevo CGPJ se constituirá con los nuevos miembros nombrados por una de las Cámaras, y los antiguos nombrados por la Cámara que no alcanza el acuerdo, y sólo, en caso, de que ambas Cámaras incumplan el CGPJ quedará en funciones.

e) Se modifican el quorum de constitución del órgano y el régimen de mayorías para la adopción de acuerdos, y se dispone que sobre el Presidente no recaerá deber

${ }^{16}$ Así lo sostuvo el propio Consejo en su Informe al Anteproyecto de Ley Orgánica de reforma del Consejo General del Poder Judicial, por la que se modifica la Ley Orgánica 6/1985, de 1 de julio, del Poder Judicial, aprobado por Acuerdo del Pleno de 6 de febrero de 2013, que puede consultarse en http:// www.poderjudicial.es. 
alguno de comparecer ante las Cámaras por razón de sus funciones más allá de la Memoria anual sobre el estado, funcionamiento y actividades del propio Consejo y de los juzgados y tribunales que debe remitirse a las Cortes Generales, pudiendo las Cortes Generales debatir el contenido de la Memoria y solicitar la comparecencia del Presidente a fin de responder a las preguntas que se le formulen en relación con la mencionada Memoria.

f) El ámbito de atribuciones del Consejo se ve también alterado, sustancialmente en lo que atañe a las potestad reglamentaria ad extra del CGPJ, se afecta de forma más puntual a la actuación internacional del mismo al exigir que su actividad internacional debe coordinarse con el Ministerio de Asuntos Exteriores, y somete su actuación presupuestaria a criterios de estabilidad y sostenibilidad presupuestaria.

Las reacciones a la reforma han sido muchas, mayoritariamente negativas: sin perjuicio de que algún aspecto haya podido merecer una valoración positiva, el saldo general no ha sido muy favorable, coincidiendo principalmente en que la nueva regulación ha restado posición institucional al CGPJ, reforzando al Ministerio de Justi$\mathrm{cia}^{17}$, no aborda los verdaderos problemas del Consejo ${ }^{18}$, como la recurrente politización ${ }^{19}$, ni sirve para atajar los que ha decidido afrontar ${ }^{20}$.

Pero las críticas no se han limitado al ámbito doctrinal, conviene tener presente que la reforma fue aprobada con los únicos votos del Partido Popular que entonces contaba con la mayoría absoluta en el Congreso necesaria para su aprobación. Por su parte, el Grupo Parlamentario Socialista del Congreso interpuso recurso de inconstitucionalidad contra determinados preceptos de la reforma, que el Tribunal Constitucional ha resuelto en la Sentencia 191/2016, de 15 de noviembre, que avala la constitucionalidad de la Ley Orgánica impugnada en su integridad, dando una interpretación conforme del art. 564 de la LOPJ, según lo razonado en el fundamen-

17 Así lo entiende Pablo Lucas Murillo de la Cueva: «La posición institucional del Consejo General del Poder Judicial y sus relaciones con los órganos constitucionales», en GERPE LANDín y CaBellos EsPiÉrrez: El Gobierno del Poder Judicial en el Estado autonómico. Evolución y perspectivas de reforma. Madrid, Marcial Pons, 2013, pág. 78.

${ }_{18}$ En concreto la reforma ni menciona ni se plantea la adaptación del órgano al modelo autonómico que rige el Estado, al respecto, Gema Rosado Iglesias: «Gobierno del Poder Judicial y Estado autonómico», en Gerpe Landín y Cabellos Espiérrez: El Gobierno del Poder Judicial en el Estado autonómico. Evolución y perspectivas de reforma. Madrid, Marcial Pons, 2013, págs. 107 y sigs.

19 Señala Íñiguez Hernández ( «a contrareforma del Consejo General del Poder Judicial», Teoría y Realidad Constitucional, núm. 34, 2014) que la última renovación del Consejo, la primera realizada conforme a los dictados de la nueva Ley, ha seguido el mismo esquema de cuotas de las anteriores, y sus miembros siguen actuando como los precedentes.

${ }^{20}$ Además de los citados Gerpe Landín y Cabellos Espíerrez, Manuel Pulido Quecedo: «El nuevo Consejo General del Poder Judicial», La Ley, año XXXIV, núm. 8126; Luis Aguiar de Luque: «Continuidad y reforma en el Régimen Jurídico del Consejo General del Poder Judicial», en LuIS Aguiar De LuQue: «Independencia Judicial y Estado Constitucional. El gobierno judicial, Valencia, Tirant lo Blanch, 2016, pág. 26. 
to jurídico 6 de la meritada Sentencia 191/2016, relativo a la comparecencia del Presidente Consejo ante las Cámaras, cuestión que se abordará más adelante.

\section{Sistema de elección, renovación del órgano y estatuto de los vocales}

La Ley Orgánica 4/2013 constituye el cuarto, y por el momento último, modelo de elección de los miembros del Consejo. No obstante, pese a introducir novedades respecto al régimen anterior no puede afirmarse que se trate de un sistema ciertamente innovador y rompedor con el hasta entonces vigente, de hecho, mantiene, pese a los intentos de la Comisión institucional e incluso a las promesas de reforma de Partido Popular acerca de la selección de vocales, la elección de todos los vocales en las Cortes Generales ${ }^{21}$, correspondiendo, en suma, la designación de diez vocales a cada una de ellas: seis de origen judicial y cuatro correspondientes al turno de juristas que han de contar con más de quince años de experiencia.

El modelo instaurado tras la reforma de 2013 no ha seguido, pues, las recomendaciones que en su día vertió el Tribunal Constitucional en su Sentencia 108/1986, en la que se enjuició la Ley Orgánica 6/1985, LOPJ, que fue la primera en introducir un cambio radical en el sistema de elección de los vocales judiciales del CGPJ, pasando de la elección por los miembros de la carrera judicial a la elección parlamentaria de todos los vocales.

Entonces el Tribunal, si bien admitió y declaró la constitucionalidad del sistema, en tanto el art. 122.3 CE remite la cuestión a la Ley y que dicha remisión aceptaba diferentes interpretaciones, entre ellas la propuesta por la Ley de reforma, advirtió (en el Fundamento jurídico 13 de la mencionada Sentencia) de sus riesgos y aconsejó su modificación.

La experiencia y práctica de los partidos políticos mayoritarios demostraría la certeza de los temores del Tribunal, poniendo de manifiesto la conducta de las grandes fuerzas políticas al pactar, no con el ánimo de obtener el consenso necesario para alcanzar la mayoría requerida de tres quintos de la Cámara para la correspondiente designación, sino para repartir el número de vocales a designar en cuotas correspondientes a la representación que cada uno de los grupos políticos mayoritarios tienen en las Cámaras legislativas.

Este riesgo y esta práctica no ha cambiado con la reforma realizada por la Ley Orgánica 4/2013, perdiéndose la oportunidad «de ceder la elección de los vocales judiciales a sus protagonistas» ${ }^{22}$ y asumir las recomendaciones del Tribunal Constitucional.

${ }^{21}$ Diego Íñiguez Hernández: «La contrarreforma del Consejo General del Poder Judicial», Teoría y Realidad Constitucional, núm. 34, 2014, págs. 337 y sigs.

22 Ascensión Elvira Perales: «Composición y elección de los miembros del Consejo General del Poder Judicial», en «Independencia Judicial y Estado Constitucional. El gobierno judicial, Valencia, Tirant lo Blanch, 2016, pág. 36. 
La reforma además introduce una disposición, el art. 567.3 LOPJ, que permite que en el cupo de juristas de reconocido prestigio se integren jueces y magistrados que no se encuentren en activo en la carrera judicial y cuenten con más de quince años de experiencia profesional, para lo que podrán computarse tanto los años de antigüedad en la carrera judicial como los dedicados al ejercicio profesional, y añade que «(q)uien, deseando presentar su candidatura para ser designado Vocal, ocupare cargo incompatible con aquél según la legislación vigente, se comprometerá a formalizar su renuncia al mencionado cargo si resultare elegido.»

Este precepto ha sido acogido muy críticamente por los autores, considerando que con ello se violenta el espíritu constitucional que pretendió y diseñó un órgano constitucional autónomo de los otros poderes del Estado que representase el pluralismo de la sociedad y no sólo el existente en la carrera judicial ${ }^{23}$.

Por cuanto afecta al sistema de elección de los vocales, las principales novedades se pueden articular en torno a tres aspectos esenciales:

a) Se opta por un modelo de presentación de candidaturas individuales, alejándose así del sistema anterior en el que el protagonismo lo ostentaban las asociaciones judiciales, y reduce el número el número avales que es necesario para la presentación de un juez o magistrado como candidato. El juez o magistrado que desee presentar su candidatura, a tenor del art. 574 LOPJ, podrá optar entre aportar el aval de veinticinco miembros de la carrera judicial en servicio activo o el aval de una asociación judicial legalmente constituida en el momento en que se decrete la apertura del plazo de presentación de candidaturas. Cada juez o magistrado o asociación judicial podrá avalar hasta un máximo de doce candidatos.

La reducción del número de avales (veinticinco frente al 2 por ciento de los miembros en activo de la carrera judicial que exigía la regulación anterior y que representaban aproximadamente unos cien avales) ha de valorarse positivamente. Así mismo, el hecho de que se trate de candidaturas individuales puede suponer cierta pérdida de control por parte de las asociaciones judiciales y animar a jueces no asociados, o no muy vinculados a asociaciones a presentarse al proceso lo que redundará en una mayor participación y pluralismo entre los candidatos a elegir.

b) En cuanto a la proporcionalidad entre los designados que deben respetar las Cámaras al proceder a la elección, el art. 578.2 LOPJ afirma que en la elección de los

${ }^{23}$ Gerpe Landín y Cabellos EspiérReZ ( «La reforma permanente...», cit., pág. 21) sostienen que «(s)i la Constitución distingue entre los 12 jueces y los 8 juristas, es porque estos últimos no se quiere que sean elegidos entre jueces, sino entre otras profesiones jurídicas, para asegurar un pluralismo interno en el órgano. La previsión legal, por tanto, puede ir directamente en contra de esa voluntad de pluralismo considerado desde el punto de vista de la extracción profesional de los vocales, y es por eso mismo muy criticable.» Crítica con esta disposición también es Rosario Serra Cristóbal: «La reforma del sistema de selección de los miembros del Consejo General del Poder Judicial», en Gerpe Landín, M., y Cabellos Espiérrez, M. A.: El gobierno del Poder Judicial en el Estado autonómico. Evolución y perspectivas de reforma, Madrid, Marcial Pons, 2013, pág. 88. 
llamados vocales judiciales aquéllas "tomarán en consideración el número existente en la carrera judicial, en el momento de proceder a la renovación del Consejo General del Poder Judicial, de Jueces y Magistrados no afiliados y de afiliados a cada una de las distintas Asociaciones judiciales. ».

En su cabal entendimiento esta previsión debiera llevar a que la designación realizada por las Cámaras tuviera en cuenta, y se tradujera lógica y correlativamente en la elección, la proporción existente entre el número de jueces y magistrados no asociados y los asociados (los no asociados representan la mitad de los miembros de la carrera judicial aproximadamente) y a todas las asociaciones judiciales. Sin embargo, tras la primera renovación del Consejo realizada conforme a los dictados de la Ley Orgánica 4/2013 cabe constatar que las cosas no han cambiado, pues, ha seguido primando la designación en favor de miembros de las dos asociaciones judiciales mayoritarias (Asociación Profesional de la Magistratura y Jueces para la Democracia), con sólo tres representantes de los no asociados, y ninguno que pertenezca a las asociaciones Francisco de Vitoria y Foro Judicial Independiente.

$Y$ es que el precepto es muy impreciso, al menos el anterior régimen fijaba, en la fase de presentación de candidaturas, un número máximo de candidatos, a la sazón, treinta y seis, entre los que debía haber proporción entre no asociados y asociados, que además debían guardar proporción en relación con la representatividad e implantación de cada asociación. Después las Cámaras decidían libremente pero en la presentación inicial de candidaturas existía una proporción inicial ${ }^{24}$.

c) El nuevo modelo introduce la necesidad de respetar una proporcionalidad entre las categorías judiciales; magistrados del Tribunal Supremo, magistrados con más de veinticinco años de antigüedad en la carrera judicial y jueces y magistrados sin sujeción de antigüedad ${ }^{25}$. Esta previsión fue muy criticada por el CGPJ en su Informe al Anteproyecto, como se ha dicho con anterioridad, al considerar que conllevaba una sobrerrepresentación, o desproporción, de los magistrados del Tribunal Supremo que no se corresponde con su número dentro de la carrera judicial. Sin embargo, dado que el precepto no impone que esta correlación se cumpla en todo caso, si no existen tres magistrados del Tribunal Supremo entre los candidatos, las vacantes acrecerán al siguiente cupo establecido (igual previsión se establece con las otras categorías), y que

\footnotetext{
24 Ahora, esto es más difícil de alcanzar, en tanto «(e)stas reglas de reparto en la configuración inicial del listado de candidatos, pues, han desaparecido, pero no se han trasladado al momento de elección por las Cámaras de los vocales judiciales, sino que se realiza una genérica referencia a que las Cámaras "tomarán en consideración» las proporciones existentes entre no afiliados y afiliados a las diversas asociaciones (art. 578.2), lo que lógicamente deviene una previsión sin apenas contenido normativo. » GERPE LANDÍn y CABELLOS ESPIÉRREZ: «La reforma permanente...», cit., pág. 17.

25 Concretamente el art. 578.3 establece que "(l)a designación de los doce Vocales del Consejo General del Poder Judicial del turno judicial deberá respetar, como mínimo, la siguiente proporción: tres Magistrados del Tribunal Supremo; tres Magistrados con más de veinticinco años de antigüedad en la carrera judicial y seis Jueces o Magistrados sin sujeción a antigüedad. Si no existieren candidatos a Vocales dentro de alguna de las mencionadas categorías, la vacante acrecerá el cupo de la siguiente por el orden establecido en este precepto.»
} 
la Constitución tampoco exige que todas las categorías estén representadas sino que todas sean elegibles, parece que la sobrerrepresentación de magistrados del Tribunal Supremo deriva no tanto del modelo establecido sino del número de vocalías reservadas a los mismos.

En cualquier caso, ni en las regulaciones precedentes (salvo en alguna medida en la primera Ley Orgánica de 1980, que también distinguía entre categorías judiciales), ni en la actual, el legislador ha demostrado verdadero interés por establecer un modelo respetuoso con la proporcionalidad y el pluralismo presente en la carrera judicial, ni en relación con el binomio jueces asociados y no asociados, ni entre categorías judiciales, ni entre las diferentes asociaciones judiciales profesionales. No hay más que ver los datos que arrojan los sucesivos procesos de designación de los vocales para constatar la realidad de esta afirmación. De hecho, una regulación que sólo contiene recomendaciones deja un amplio margen de maniobra a las Cámaras a la hora de proceder a la designación de los cargos y esto es, desde luego, lo que parece primar en la voluntad de nuestros representantes.

Valoración positiva merece, sin embargo, que, según prevé el art. 567.4 LOPJ, en la elección que realizan las Cámaras parlamentarias se deban incluir tres suplentes, uno por cada uno de los turnos, indicándose el orden de sustitución, lo que permitirá cubrir las vacantes producidas sin necesidad de proceder a una nueva elección parlamentaria, y evita el mantenimiento de la eventual vacante sin cubrir durante un plazo que a veces ha llevado a su no cobertura, con los inconvenientes que esta situación pueda producir en la adopción de acuerdos y formación de las mayorías requeridas por la Ley.

Favorable también es el parecer que cabe realizar a la prohibición contenida en el art. 584 LOPJ, que impide que los vocales puedan ser promovidos, durante su mandato, a la categoría de Magistrado del Tribunal Supremo o a Magistrado del Tribunal Constitucional, ni nombrados para cualquier cargo de la carrera judicial de libre designación o en cuya provisión concurra apreciación de méritos. Práctica de la que hay ejemplos sobradamente conocidos.

Pero sí hay dos aspectos que han sido ampliamente criticados y que incluso han fundado el recurso de inconstitucionalidad que presentó el Grupo Socialista del Congreso: me refiero al proceso de renovación del órgano y a la pérdida de la dedicación exclusiva de los miembros del Consejo, salvo los integrantes de la Comisión permanente y el Presidente.

Por lo que se refiere al proceso de renovación de los vocales, el art. 570 introduce una previsión que pretende solventar las situaciones de bloqueo que se producen cuando en una de las Cámaras, o ambas, no alcanza la mayoría necesaria para proceder a la designación de nuevos vocales, y que derivaba en una situación de interinidad del órgano, a su prorrogatio, hasta el momento en que se produjera la designación parlamentaria completa del órgano; situación que no es desconocida, y que incluso ha llegado a suponer la actuación en funciones del Consejo hasta dos años de la finalización de su mandato (concretamente, el Consejo que se renovó en 2008 debía haber 
sido renovado en 2006 cuando finalizó el periodo de cinco años para el que había sido designado).

La previsión que incorpora la reforma a este respecto es verdaderamente novedosa, e inusual. Algunos autores han defendido que se debería establecer una prohibición de prorrogatio ${ }^{26}$, otros se decantan por una renovación por tercios similar a la del Tribunal Constitucional ${ }^{27}$, o por el cese de todos los vocales salvo los miembros de la Comisión permanente que podría seguir manteniendo el funcionamiento habitual y regular de la institución, singularmente en materias que tienen importantes efectos y consecuencias en el funcionamiento del propio Poder Judicial ${ }^{28}$.

Como se ha dicho, el Grupo Socialista del Congreso presentó recurso de inconstitucionalidad, que ha sido rechazado por el Tribunal Constitucional, declarando la constitucionalidad de la previsión, por entender que la renovación del órgano en su integridad es una opción legítima del legislador, pero que no queda garantizada con plenitud y eficacia por el solo enunciado vinculante de la norma, por lo que no puede haber objeción constitucional a que el legislador disponga prevenciones secundarias para el caso de que tal renovación conjunta no se produzca ${ }^{29}$. En consecuencia, sostiene el Tribunal que la regulación contenida en el art. 570 LOPJ no constituye una renovación parcial del órgano, sino una previsión subsidiaria de la regla general que determina la renovación íntegra.

El otro aspecto que queda por valorar es el relativo a la compatibilidad de los vocales designados con el ejercicio de las funciones que vinieren realizando hasta el momento, sea como miembros en activo de la carrera judicial sea en sus funciones profesionales como juristas ajenos al Poder Judicial. Esta previsión ha merecido valoraciones tanto favorables como desfavorables ${ }^{30}$, siendo ampliamente criticada por el CGPJ en su Informe al Anteproyecto de Ley y objeto de recurso de inconstitucionalidad, que, por cierto, prácticamente reproduce las razones aducidas por el entonces CGPJ que pivotan esencialmente en torno a la prohibición para jueces y magistrados que contiene el art. 127.1 CE.

26 En concreto JuAn Alfonso SANTAMARÍA PASTOR: «La prorrogatio de los órganos constitucionales. Apuntes mínimos sobre un tema que no lo es», Revista Española de Derecho Constitucional, núm. 84, 2008, págs. 24-25. Elvira Perales («Composición y elección...», cit., p. 43), vincula tal prohibición que preveía la propuesta de la Comisión institucional con el sistema de selección de vocales que establecía.

27 Así Manuel Pulido Quecedo: «El nuevo Consejo General del Poder Judicial», La Ley, año XXXIV, núm. 8126, 15 de julio de 2013, págs. 25-27.

${ }^{28}$ En este sentido expresamente LUIS AGUIAR DE LUQUE: «Una nueva reflexión sobre la prorrogatio de los órganos constitucionales. Una discrepancia y algunas precisiones a J.A. Santamaría», Revista Española de Derecho Constitucional, núm. 85, 2009, p. 97, entiende que la mencionada prohibición no garantiza el cumplimiento por las Cámaras, y que se provocaría un grave funcionamiento en el Poder Judicial habida cuenta de que hay funciones que sólo pueden realizarse por el CGPJ, proponiendo, como se afirma en el texto, como salida a tal situación de interinidad, el cese inmediato de todos los vocales menos los integrantes de la Comisión Permanente.

29 Fundamento Jurídico 8 de la Sentencia 191/2016.

30 Diego Í̃̃iguez HernándeZ: «Regreso al siglo XIX», en El País, 11 de diciembre de 2013. Elvira Perales: «Composición y elección....», cit., pág. 42. 
Sin embargo, el Tribunal Constitucional, acogiendo la tesis del Abogado del Estado, declara que «la probibición ex art. 127.1 CE de que Jueces y Magistrados, mientras estén en servicio activo, no desempeñen otros cargos públicos está dirigida, inequívocamente, a cargos ajenos al ámbito propiamente judicial, condición que no se da, como es obvio, en la de vocal del Consejo General del Poder Judicial, órgano no jurisdiccional, desde luego, pero al que corresponde, por ministerio de la Constitución, el gobierno, precisamente, del Poder Judicial (art. 122.2 CE). La probibición del repetido art. 127.1 CE no alcanza a los cargos y funciones que se integran y se ejercen en el ámbito judicial y, específicamente, en el de su gobierno» ${ }^{31}$.

Por demás, como sostiene el Tribunal, el que los vocales judiciales en activo puedan encontrarse ante situaciones que deban derivar en su abstención o justificar su recusación, nada dice de la constitucionalidad de la norma legal, en la medida en que el ordenamiento dispone de instrumentos para solventar estas situaciones. En definitiva, la opción por la compatibilidad de la actividad de miembro del CGPJ con su función jurisdiccional y con otras funciones judiciales «es una opción que corresponde, de nuevo, a la libre disposición del legislador orgánico y que, aunque pueda suscitar polémicas políticas o de oportunidad, no merece censura constitucional.»

De otra parte, gran parte de las críticas no atienden a motivos de inconstitucionalidad. El afirmar que supone establecer categorías o clases entre los vocales ${ }^{32}$, el menor conocimiento e información que gran parte de los vocales pueden tener para ejercer sus funciones en el Pleno y adoptar las decisiones pertinentes, la no imposición obligatoria de la renovación anual de la Comisión Permanente, o la exclusión de los miembros de la Comisión disciplinaria del proceso de alternancia en la composición de la Comisión permanente, son cuestiones muy a tener en cuenta para valorar la conveniencia y oportunidad, la efectividad y eficacia de la norma que ahora analizamos, pero que, por si mismas, no sirven de fundamento a su eventual inconstitucionalidad.

Por otro lado, la eficacia y justificación de una medida como esta debe ser correlativa a una redefinición de las funciones del Consejo, de forma que este órgano se concentre en el ejercicio de funciones que le atribuye la Constitución, que son las que han justificado su creación y que tiene como finalidad la garantía de la independencia judicial. Mantener, o modificar mínimamente, las competencias del CGPJ y establecer la compatibilidad puede afectar al funcionamiento del órgano. De hecho, esta parece ser la razón que está detrás de la elevación del número de vocales que forman la Comisión Permanente, que a partir de la reforma operada por la Ley Orgánica 7/2015, han pasado de cinco a siete, más el Presidente, que sí tienen dedicación exclusiva.

31 Fundamento jurídico 9 de la Sentencia 191/2016.

32 Í̃̃IgUEZ: «Regreso al siglo XIX», cit. Pese a la remisión al legislador que contiene el art. 122.2 $\mathrm{CE}$, parece que pensase en unos miembros con el mismo estatuto y régimen de incompatibilidades, lo que lleva a Lucas Murillo de la Cueva («La posición institucional del Consejo General del Poder Judicial...», cit., pág. 77) a dudar de su constitucionalidad. 
La Exposición de Motivos justificó esta modificación del estatuto de los vocales al entender que favorecería la cercanía de los vocales con la realidad que debían atender, contribuiría a una buena administración y eficacia económica de la institución, razón que el CGPJ en su informe consideró que pesó notablemente, y que permitiría acceder al CGPJ a personas, tanto pertenecientes a la carrera judicial como a otros ámbitos jurídicos profesionales, que hasta el momento no habían mostrado interés en participar en el órgano para no alejarse de su actividad profesional.

Lo cierto es que todas estas razones no poseen entidad suficiente ${ }^{33}$ para justificar mínimamente esta medida. Por supuesto que es una cuestión que debe decidir el legislador, al que se remite el art. 122.2 para regular el estatuto y régimen de incompatibilidades de los miembros del CGPJ, pero su adopción debería haberse acompañado de una verdadera reforma de las atribuciones del órgano de gobierno del Poder Judicial para ajustarlas a los términos constitucionales, o bien optar directamente por la reforma constitucional, bien para reducir el número de vocales, bien para definir de forma más concreta el órgano y sus funciones. De hecho, el Comité Consultivo de Jueces Europeos, órgano asesor del Comité de Ministros del Consejo de Europa, destaca que la dedicación a tiempo completo de los integrantes de los Consejos de Justicia «significa una mayor eficacia del trabajo y salvaguardia de su independencia» ${ }^{34}$.

De otro lado, la experiencia del primer Consejo nombrado conforme a este modelo ha demostrado que la diferencia entre vocales es una realidad, que gran parte de ellos se sienten desplazados y que no poseen la información y documentación previa necesaria, con la anterioridad suficiente y el tiempo para abordarla, en materias que han de ser decididas por el Pleno ${ }^{35}$.

Complementariamente, esta previsión también ha de interpretarse a la luz del eventual reforzamiento de la posición de los letrados, a cuyos Jefes de Servicio, a tenor del art. 602.2 LOPJ, se podrá atribuir competencias en supuestos no reservados al Pleno, que no supongan ejercicio de funciones discrecionales ${ }^{36}$. Este precepto, sin

33 Como ponen de manifiesto Gerpe Landín y Cabellos Espiérrez: «La reforma permanente...», cit., págs. 24 y sigs.

34 El Consejo de la Justicia al servicio de la sociedad, Informe 10, aprobado en la reunión plenaria celebrada en Estrasburgo los días 21 a 23 de noviembre de 2007. Este informe puede consultarse en http://www.poderjudicial.es/cgpj/es/Temas/Relaciones-internacionales/Relaciones-internacionales-institucionales/Europa/Consejo-Consultivo-de-Jueces-Europeos/

${ }_{35}$ No hay más que leer los numerosos votos particulares que reflejan esta situación, especialmente los formulados por el vocal Enrique Lucas Murillo de la Cueva. Se pueden consultar en http://www. poderjudicial.es. También así lo manifiesta LuCas Murillo De la Cueva: «La posición institucional del Consejo General del Poder Judicial...», cit., pág. 78.

36 A este reforzamiento también se refería la Exposición de Motivos aseverando que «el nuevo diseño de la organización y funcionamiento del Consejo General del Poder Judicial permite que parte del trabajo desarrollado por este órgano, incluida la tramitación y preparación de los asuntos sobre los que deben adoptarse acuerdos, sea llevado a cabo por los funcionarios del Cuerpo de Letrados». Afirmación que ha 
embargo, no fue objeto de recurso de inconstitucionalidad, y no se ha aplicado plenamente, seguramente porque todavía, a pesar de que el mandato del Consejo actual finaliza en diciembre de 2018, es decir, que lleva ya prácticamente cuatro años de funcionamiento en aplicación de la nueva Ley Orgánica 4/2013, y de los trabajos internos al efecto, no ha sido aprobado un nuevo Reglamento de Organización y Funcionamiento del Consejo ${ }^{37}$.

\section{Estructura orgánica del Consejo General del Poder Judicial y cuestiones relativas al funcionamiento de los órganos}

La Ley Orgánica 4/2013 contiene una verdadera reformulación de la estructura orgánica del CGPJ. Si hasta el momento el Pleno venía constituyendo el órgano principal decisor del Consejo, a partir de la reforma de 2013 el Pleno pasa ciertamente a un segundo lugar, cediendo el protagonismo a la renovada Comisión permanente, que se erige como el órgano de funcionamiento y decisión del órgano de gobierno del Poder Judicial ${ }^{38}$.

Aunque algunos han querido ver en esta decisión una forma de posibilitar el control o la injerencia del ejecutivo en el CGPJ, así lo entendió el Informe del CGPJ emitido con motivo del Anteproyecto de Ley Orgánica, al hacer recaer la mayoría de las decisiones en un órgano de composición reducida, que se renovará,

llevado a que parte de la doctrina se replantee si no se trata de una reformulación del órgano que excedería los límites constitucionales. Gerpe Landín y Cabellos Espiérrez: «La reforma permanente...», cit., pág. 25.

${ }^{37}$ Sigue, pues, aplicándose y rigiéndose el Consejo en su funcionamiento en todo aquello que no resulte contrario a la Ley Orgánica 4/2013, por el Reglamento 1/1986, de 22 de abril, de organización y funcionamiento del Consejo General del Poder Judicial, modificado por el Acuerdo de 2 diciembre de 1998, del Pleno del Consejo General del Poder Judicial, por el que se aprueba el Reglamento 1/1998, del Consejo General del Poder Judicial, de tramitación de quejas y denuncias relativas al funcionamiento de los Juzgados y Tribunales y se modifica el Reglamento 1/1986, de 22 de abril, de organización y funcionamiento del Consejo General del Poder Judicial; por el Acuerdo del Pleno del Consejo General del Poder Judicial de 25 de junio de 2008, por el que se modifica el Reglamento 1/1986, de 22 de abril, de organización y funcionamiento del Consejo general del Poder Judicial, y por el Acuerdo de 25 de febrero de 2010, del Pleno del Consejo General del Poder Judicial, por el que se aprueba el reglamento $1 / 2010$, que regula la provisión de plazas de nombramiento discrecional en los órganos judiciales.

${ }^{38}$ Conclusión a la que se llega tras la lectura del articulado, y pese a lo sostenido en la Exposición de Motivos de la Ley en cuanto a que «todas las decisiones auténticamente relevantes siguen en manos del Pleno», sin que exista "un desapoderamiento del Pleno, ni un menoscabo del lugar central que ocupa». Sobre la nueva posición de la Comisión permanente Francisco Javier Donaire Villa: «La renovada configuración de la Comisión Permanente del Consejo General del Poder Judicial tras la Ley Orgánica 4/2013», en Luis Aguiar de Luque: «Independencia Judicial y Estado Constitucional. El gobierno judicial, Valencia, Tirant lo Blanch, 2016, págs. 51 y sigs. Del mismo autor, «La nueva regulación legislativa de la Comisión Permanente del Consejo General del Poder Judicial: ¿reforma legal o mutación constitucional?», Revista Vasca de Administración Pública, núm. 105, 2016, págs. 103 y sigs. 
o al menos según la Ley se procurará su renovación, anualmente, y de cuya renovación quedan excluidos los miembros de la Comisión disciplinaria, la Constitución, cuando atribuye competencias al Consejo, lo hace al órgano en su conjunto, remitiendo a la Ley Orgánica su configuración, y el diseño de su estructura orgánica, sin determinar que las funciones residenciadas en el órgano de gobierno deban realizarse por un órgano concreto de los que articulan su estructura orgánica. Por demás, el Consejo, como el resto de los órganos constitucionales y poderes públicos, se expresa a través de sus órganos y es a éstos a los que, de acuerdo con la habilitación legal y en el ámbito de sus competencias, corresponden ejercer las funciones que la Constitución y la propia Ley Orgánica encomiendan al $\mathrm{CGPJ}^{39}$.

Pues bien, dicho lo anterior, la nueva estructura orgánica del Consejo se configura en torno a tres órganos principales: Pleno, Comisión Permanente y Comisión Disciplinaria. Existen además otras dos Comisiones legales, la de Igualdad y la de Asuntos Económicos, con funciones muy limitadas, residuales en su ámbito competencial, preparatorias (nunca decisorias) de las decisiones que deban adoptar otros órganos, en concreto, Pleno y Comisión permanente, principalmente ésta última.

La nueva organización oficiada por la Ley de reforma introduce también dos nuevas figuras en la actuación y funcionamiento del Consejo, a saber, el Promotor de la Acción Disciplinaria y el Vicepresidente del Consejo, que existía con anterioridad, pero cuya definición y designación es ahora esencialmente distinta.

Volviendo al diseño estructural del Consejo, se advierte una profunda renovación de los órganos decisores, que se traduce en una pérdida del protagonismo y de la hegemonía del Pleno en favor de la Comisión permanente, cuyo peso específico entre los órganos del Consejo la convierten en el verdadero eje central del funcionamiento y decisión del CGPJ ${ }^{40}$, que suma además a sus competencias las que con

39 La opinión de la doctrina no es pacífica en todo caso, críticos han sido con el nuevo modelo Julio BanaCloche PalaO: «La insólita reforma de la organización y funcionamiento del Consejo General del Poder Judicial», Diario la Ley, núm. 8126, 15 de julio de 2013, pág. 5. Pulido QuECEDo «El nuevo Consejo General del Poder Judicial», cit., Cuestionándose algunos autores su constitucionalidad, Ángel Dolado Pérez: «Valoración del nuevo Consejo del Poder Judicial», Diario la Ley, núm. 8126, 15 de julio de 2013, pág. 2, e Í̃̃iguez Hernández: «La reforma del Consejo General del Poder Judicial en España. Noticia de otra reforma fallida», cit., pág. 155. Por su parte Luis Aguiar de LuQue [ «Las recientes reformas en materia de Poder Judicial en su dimensión orgánica», en Miguel Revenga SÁnchez (coord.): El Poder Judicial. VI Congreso de la Asociación de Constitucionalistas de España, Tirant lo blanch, Valencia, 2009, págs. 49-52], defendió la configuración de un órgano interno de composición reducida que asumiera gran parte de las funciones del Consejo, bajo el control del Pleno.

40 Rosa M. ${ }^{a}$ Fernández Riveira: «Nuevos enfoques de la independencia judicial. Dos puntas del iceberg en la reforma de la Ley Orgánica del Poder Judicial: la Comisión permanente del CGPJ y el Gabinete técnico del Tribunal Supremo», Teoría y Realidad Constitucional, núm. 38, 2016, pág. 375 y sigs. 
anterioridad venía realizando la Comisión de calificación que desaparece con la Ley Orgánica 4/2013.

A la luz de esta distribución competencial entre los órganos del Consejo, adquiere sentido, funge como justificación según la Exposición de Motivos, que sólo un número reducido de vocales, los que componen la Comisión permanente, gocen de exclusividad, y que, en base a esos supuestos motivos de agilidad y eficiencia, el órgano decisor se integre por un reducido número de miembros, que, con todo, y como se ha dicho, ha sido ampliado en 2015 ante la aparente falta de capacidad de los cinco miembros originales (más el Presidente) para asumir el conjunto de atribuciones encomendadas a este órgano. Lo que nos lleva nuevamente a preguntarnos si no habría sido más adecuado proceder a una reforma constitucional que redujese el número de miembros del Consejo y ajustase sus competencias estableciendo como, como ahora, el núcleo estricto de las competencias y referenciando aquellas otras que pueda atribuirle la Ley Orgánica en función de su naturaleza y función constitucional como órgano de gobierno del Poder Judicial .

A lo anterior han de sumarse otros dos nuevos elementos que patentizan aún más la potenciación y reforzamiento de la Comisión permanente. Me refiero a la supresión del recurso de alzada ante el Pleno y contra las decisiones de la Comisión permanente, que serán directamente impugnables ante la jurisdicción contencioso-administrativa (art. 638.2 LOPJ), de un lado, y a la suerte de relación de dependencia/jerarquía que parece establecerse entre el Promotor de la Acción Disciplinaria y la Comisión Permanente.

Pues bien, esta falta absoluta de revisión de los acuerdos de la Comisión Permanente por el Pleno sí puede ser cuestionable (incluso autores que defendieron la creación de un órgano interno reducido como centro de decisión de las funciones principales del Consejo, pusieron de relieve que debiera mantenerse el recurso de alzada ante el Pleno, que éste fuera el órgano de control ${ }^{41}$, o que el Pleno mantuviese las competencias pero actuase a propuesta de la Comisión Permanente ${ }^{42}$ ), máxime si tenemos en cuenta que la atribución de competencias al Pleno, mediante un elenco cerrado y taxativo de funciones y materias, en tanto el art. 599 LOPJ afirma que el plenario «conocerá exclusivamente», parece excluir cualquier forma de avocación de las competencias de la Comisión permanente ${ }^{43}$.

41 Luis López Guerra: «El Consejo General del Poder Judicial. Evaluación y propuestas de reforma», Fundación Alternativas. Documento de trabajo 18/2003, págs. 31-32.

42 Aguiar de LuQue: «Las recientes reformas....», cit., pág. 51.

43 Como dice Javier Pérez Minaya («Crónica de una muerte anunciada. Breve autopsia del Consejo General del Poder Judicial», Diario La Ley, núm. 8216, 15 de julio de 2013), "nos encontramos ante un fenómeno de concentración en una parte, que, además se encuentra jurídicamente aislada e independiente del todo ¿Alguien se imagina que el Secretario de Justicia pudiera adoptar decisiones sin facultad de control y revisión por el Sr. Ministro de Justicia? El Pleno no tiene facultad legal de revisar y dejar sin efecto acuerdos de la Permanente». 
El significativo peso específico que la Ley Orgánica atribuye a la Comisión se aprecia así mismo en la dependencia funcional, que no orgánica en tanto el Promotor no es órgano del Consejo, sino subordinado al mismo, como dice la Exposición de Motivos, que se establece entre el Promotor de la Acción Disciplinaria y la Comisión Permanente, que se traduce en la posibilidad de interponer recurso ante la Comisión permanente frente a la decisión del Promotor de no iniciar expediente disciplinario o de archivar uno ya iniciado (art. 608.1 LOPJ). Si el recurso así impetrado fuese estimado se iniciará o continuará el expediente disciplinario de que se trate. Pero además, dispone el apartado tercero de este mismo precepto, la «Comisión permanente también podrá, de oficio, ordenar al Promotor de la Acción Disciplinaria la iniciación o continuación de un expediente disciplinario».

Que estas facultades revisores y esta dependencia funcional se haya establecido en relación con la Comisión permanente y no en relación con la Comisión disciplinaria se explica en la finalidad que advierte la Exposición de Motivos de la Ley de reforma de profundizar en la separación entre las funciones instructoras y sancionadoras y potenciar las garantías en este procedimiento administrativo-sancionador, de modo que se asiente con plenitud sobre el principio acusatorio, frente al principio inquisitivo que regía con anterioridad ${ }^{44}$.

En definitiva, la creación del Promotor de la Acción Disciplinaria y las modificaciones introducidas en la Comisión Disciplinaria configura un nuevo reparto de funciones en el ejercicio de la potestad disciplinaria del Consejo que impide que un mismo órgano decida sobre la incoación del procedimiento, designe al instructor y decida sobre la imposición o no de la sanción ${ }^{45}$.

Este reparto y distribución funcional supone configurar al Promotor como órgano instructor del expediente disciplinario ${ }^{46}$, que es ahora un órgano único, modifi-

${ }^{44}$ Sobre el modelo anterior, Gema Rosado IgLesias: «El ejercicio de la función disciplinaria por el Consejo General del Poder Judicial», en Miguel Revenga SÁnchez (coord.): El Poder Judicial. VI Congreso de la Asociación de Constitucionalistas de España, Tirant lo blanch, Valencia, 2009, págs. 193 y sigs.

${ }^{45}$ En la regulación anterior, al menos en relación con las faltas graves, todas estas potestades eran ejercidas por la Comisión Disciplinaria. Al respecto más en detalle, Rosado IGLESIAS: «El ejercicio de la función disciplinaria....», cit. Sobre el nuevo régimen explicado de forma pormenorizada que no es posible abordar en este trabajo, Gema Rosado Iglesias y Ana Espinosa DíaZ: «Independencia judicial y poder disciplinario judicial», en LuIs AGUIAR DE LuQue: «Independencia Judicial y Estado Constitucional. El gobierno judicial, Valencia, Tirant lo Blanch, 2016, págs. 101 y sigs.

${ }^{46}$ Su nombramiento corresponde al Pleno, para un mandato que coincidirá con el del Consejo que lo nombró, entre Magistrados del Tribunal Supremo y Magistrados con más de veinticinco años de antigüedad en la carrera judicial. En primera votación será elegido quien obtenga la mayoría absoluta y si nadie la alcanzara, en segunda votación será elegido el que obtenga mayor número de votos. El Promotor permanecerá en servicios especiales en la carrera judicial, ejerciendo exclusivamente las funciones inherentes a su cargo, pudiendo ser cesado únicamente por incapacidad o incumplimiento grave de sus deberes, apreciados por el Pleno por mayoría absoluta. En el caso de que se dieran circunstancias excepcionales, físicas (como sería el caso de enfermedad), o legales (que habrá que entender referidas a la concurrencia de causas de abstención o de recusación), que supusieran para el Promotor la imposibilidad 
cándose el régimen anterior que conlleva la designación de un instructor concreto para cada caso específico y dejar a la Comisión Disciplinaria como órgano decisor en los procedimientos por infracciones graves o muy graves (las faltas leves serán, en su caso, sancionadas por las Salas de Gobierno de los Tribunales o sus Presidentes, según la sanción que lleven aparejada), salvo aquellos en que el Promotor proponga, por su extrema gravedad, la imposición de la sanción de separación del servicio, cuya resolución se atribuye al Pleno.

Por lo que respecta a la Comisión Disciplinaria se regula ahora con importantes singularidades en relación con las otras Comisiones del Consejo (que tras la reforma de 2015 sólo cuentan con tres miembros), de un lado, es la más extensa en su composición, que alcanza hasta siete miembros, como la Comisión permanente, cuatro del turno judicial y tres del turno de juristas de reconocida competencia, y de otro, salvo las sustituciones que procedan, su mandato será de cinco años, es decir, son los únicos que permanecen en la misma Comisión durante todo el mandato del Consejo. Esta continuidad en los vocales de la Comisión Disciplinaria durante todo el mandato, el carácter inalterable de esta Comisión, si bien puede permitir una continuidad en los criterios aplicados en el ejercicio de la potestad disciplinaria (unidad y continuidad de criterios que también resulta esperable de la figura del Promotor de la Acción Disciplinaria, frente a la dispersión anterior de esta función), crea una situación de eventual desigualdad en tanto impide que estos vocales puedan formar parte de la Comisión Permanente, única en que los vocales gozan de un estatuto de exclusividad de la función (art. 579.2 LOPJ) ${ }^{47}$. Pero además, si de los miembros de la Comisión disciplinaria se ha de exigir y esperar independencia, bien parece que hubiera estado justificado dotar a sus miembros de un estatuto de exclusividad, máxime dada la imposibilidad de que los mismos formen parte de la Comisión permanente ${ }^{48}$.

De otra parte, la reforma citada no alcanzó a los principios del procedimiento sancionador que recoge la misma ley, salvo los que se vislumbran y pueden deducirse de la creación de la nueva figura del Promotor de la Acción Disciplinaria, y del nuevo régimen de reparto de competencias disciplinarias y sancionadoras entre los órganos del Consejo. De hecho, no han faltado críticas a esta modificación parcial de la cuestión y a las eventuales discordancias, dudas, lagunas y vacíos normativos que pueden generarse de la conjugación del nuevo régimen competencial con un proce-

transitoria de ejercer sus funciones, la Comisión Permanente proveerá, sólo durante el tiempo de esa imposibilidad, a su sustitución nombrando a un Magistrado que reúna los mismos requisitos exigidos para la designación de cargo del Promotor.

47 En el mismo sentido se manifiestan los vocales Gabriel Bravo Sanestanilao y José Manuel Gómez Benítez, en su voto particular formulado al Acuerdo del Pleno de 6 de febrero de 2013, por el que se aprueba el Informe del Consejo al Anteproyecto de Ley Orgánica de reforma del Consejo General del Poder Judicial.

48 En el mismo sentido Gerpe Landín y Cabellos Espíerrez: «La reforma permanente....», cit., pág. 33. 
dimiento establecido sobre unas bases de reparto competencial estructural y conceptualmente diferentes ${ }^{49}$; lo que cobra especial importancia en una materia tan sensible y con consecuencias tan importantes para jueces y magistrados, titulares de la potestad jurisdiccional, como es el ejercicio de la potestad disciplinaria y la eventual imposición de sanciones.

Otra de las reformas que más polémica han generado en torno a la nueva estructura orgánica del Consejo es la atribución de la Vicepresidencia del Consejo a quien no es miembro del mismo ${ }^{50}$, pero que puede llegar a serlo ocasionalmente en casos de sustitución del Presidente, e incluso presidir, en tal caso y dadas las circunstancias de imposibilidad del Presidente previstas legalmente, el Pleno y la Comisión Permanente, actuando en funciones de Presidente de tales órganos; consideraciones que el Grupo Socialista del Congreso entendió que vulneraban los dictados del art. 122.3 CE, en tanto el Vicepresidente, que no es miembro del Consejo, pueda llegar a presidirlo en los casos previstos en los arts. 590 y 591.1 LOPJ.

El Tribunal, en su Sentencia 191/2016 (Fundamento jurídico 10), rechaza esta tacha de inconstitucionalidad sosteniendo que "(l) a relación de sustitución no supone, en Derecho público, que las competencias de un determinado órgano (aquí, la presidencia del Tribunal Supremo) sean ejercidas por otro (la vicepresidencia del propio Tribunal, en lo que abora hace al caso), sino que el titular de cierto órgano pase a serlo también, por llamamiento legal, de otro órgano distinto, a cuyo titular quoad titulum originario sustituye, de modo tal que quien viene llamado por ley a sustituir es, en tanto lo haga, titular en funciones, quoad exertitium, del órgano cuyas competencias ejerce temporal o circunstancialmente.»

Y salda la cuestión afirmando que «el Consejo General del Poder Judicial no es órgano de representación. No lo es, desde luego, del Poder Judicial (SSTC 45/1986, FJ 5, y 108/1986, FJ 9) y tampoco su Presidente representa a los vocales del órgano, sino al órgano

${ }^{49}$ Así, el Informe al Anteproyecto de Ley Orgánica de reforma del Consejo General del Poder Judicial, de 21 de febrero de 2013, emitido por el Consejo Fiscal, señala «la deficiencia sistemática en que incurre el Anteproyecto al introducir el cargo de Promotor de la Acción Disciplinaria al regular la estructura orgánica del CGPJ sin hacer las necesarias adaptaciones en sede de procedimiento disciplinario —arts. 423 y ss LOPJ—» (este documento puede consultarse en http:///www.fiscal.es). El informe emitido por el Pleno del Consejo General del Poder Judicial con ocasión del mismo Anteproyecto (aprobado por Acuerdo de 6 de febrero de 2013, y que cuenta con numerosos votos particulares), da cuenta de las posibles incoherencias e incertidumbres normativas que la convivencia de ambas regulaciones plantea y la ausencia de una previsión de estas cuestiones en el entonces Anteproyecto de Ley Orgánica, y finalmente añade que «sería procedente aprovechar la reforma para abordar la regulación del procedimiento sancionador, la caducidad $y$ la revisión de la tipificación de las infracciones y de las sanciones a imponer». Entre los votos particulares emitidos respecto al Informe mayoritario del Pleno, el presentado por los vocales Gabriela Bravo Sanestanislao y José Manuel Gómez Benítez refleja esta preocupación al aconsejar que «el legislador aborde con urgencia la elaboración de un reglamento del procedimiento disciplinario, que sustituya a las normas de la LOPJ que lo regulan actualmente» (el texto de este Informe y de los votos particulares puede verse en http://I www.poderjudicial.es).

50 En el mismo sentido Gerpe Landín y Cabellos EspíErrez: «La reforma permanente....», cit., pág. 33. 
mismo (art. 598.1 LOPJ)», pero, más allá de la disquisición teórico-dogmática de la relación de sustitución en Derecho público, no entra en las consecuencias y trascendencia que derivan de esta regulación, como es el hecho de que el Vicepresidente, actuando en funciones de Presidente y en las circunstancias legalmente contempladas, intervenga en órganos decisores y pueda condicionar, con su voto de calidad ( qquien presida tendrá voto de calidad en caso de empate», reza el art. 630 LOPJ in fine), la decisión del órgano ${ }^{51}$.

De hecho, en alguna ocasión los vocales han cuestionado la participación del Vicepresidente en determinadas sesiones de la Comisión Permanente, por ausencia del Presidente, en las que se votó, entre otros temas, la composición de ternas para acceder a las plazas vacantes del Tribunal Supremo (pues, recuérdese que, como se dijo, la Comisión permanente ejerce ahora las funciones que antes realiza la Comisión de calificación $)^{52}$.

Otro de los aspectos que han merecido críticas y sobre los que ha declarado el Tribunal Constitucional en la meritada Sentencia, lo constituye la modificación del régimen de adopción de acuerdos por los órganos colegiados del CGPJ, que pasa de la mayoría cualificada en determinadas materias que prescribía la regulación anterior, a la mayoría simple de los miembros presentes, como regla general que establece el art. 630.1 LOPJ. Evidentemente esta opción, en los márgenes de libertad de configuración del legislador, puede evitar situaciones de bloqueo, pero también es cierto que esto hará las decisiones menos transaccionales, menos consensuales, limitando las posibilidades reales de negociación ${ }^{53}$.

Frente a este argumento, que por supuesto es una razón que sirve a la valoración de la oportunidad y la adecuación de la reforma, pero no por sí mismo de su inconstitucionalidad, sostiene el Tribunal, en el Fundamento jurídico 11 de la Sentencia 191/2016, que el Consejo no es un órgano «que deba organizarse conforme al pluralismo político que proclama como valor superior del Ordenamiento aquel precepto constitucional (...), no es el Consejo General del Poder Judicial, cabe reiterar, institución de representación, sino de garantía» ${ }^{54}$. Aserto que no deja de producir perplejidad, toda vez que el mismo Tribunal, en la Sentencia 108/1986, constató que la composición del Consejo debía acoger y, por tanto, expresar el pluralismo presente en la organización judicial y en la propia sociedad, pluralismo que se trasladaría a su actuación y, en esa medida, a las decisiones que serían, en consecuencia, expresión de esa composi-

51 Así también se manifiesta Emilio Pajares Montolío: «Consejo General del Poder Judicial y Tribunal Supremo», en LuIS AgUIAR DE LUQUE: «Independencia Judicial y Estado Constitucional. El gobierno judicial, Valencia, Tirant lo Blanch, 2016, pág. 210.

52 «Vocales del CGPJ cuestionan que Juanes haya votado para elegir a los aspirantes a magistrados del TS», Iustel diario del Derecho, 15 de enero de 2016, en http://www.iustel.com/diario_del_derecho.

53 María Luz Martínez Alarcón: «El Tribunal Constitucional avala la constitucionalidad de la reforma del Consejo General del Poder Judicial del año 2013. La Sentencia 191/2016, de 15 de noviembre», Revista General de Derecho Constitucional, núm. 24, 2017.

54 Fundamento jurídico 11 de la Sentencia 191/2016. 
ción plural; lo que resulta especialmente significativo en materias de indudable relevancia, individual y social, como son las decisiones relativas al nombramiento de altos cargos judiciales. ${ }^{55}$

Desde esta perspectiva, no ofrece duda que el recurso a la mayoría simple como regla general para la adopción de acuerdos, incluidos los concernientes a los nombramientos mencionados, facilitará el acuerdo a costa de relegar a las posiciones distintas a la mayoritaria y conllevará a una concentración de poder en manos de la mayoría que resulta difícilmente conciliable con la vocación pluralista para el Consejo que alimentaba la Sentencia 108/198656. Eliminar el riesgo de bloqueo en el ejercicio de la función no parece, de principio y por sí mismo, que deba primar sobre el valor del pluralismo que el Tribunal demandaba para un órgano que tiene encomendada la garantía de la independencia judicial ${ }^{57}$.

En cuanto al régimen de revisión de los acuerdos aprobados por los órganos del Consejo, como se ha mencionado con anterioridad, las decisiones del Pleno y de la Comisión Permanente son recurribles directamente ante la jurisdicción contencioso-administrativa, no cabiendo recurso de alzada en vía administrativa. Las decisiones adoptadas por la Comisión disciplinaria serán recurribles en alzada ante el Pleno; competencia que ha sido objeto de cierta crítica, dado que el Pleno está compuesto por todos los vocales del Consejo y, por tanto, también por los que forman la Comisión Disciplinaria que, así, resolverían en alzada sobre su propia decisión.

El Tribunal Supremo ha tenido oportunidad de pronunciarse sobre la posible obligación de abstenerse en la toma de estas decisiones de los vocales de la Comisión

55 En este sentido coincido con Martínez Alarcón («El Tribunal Constitucional avala la constitucionalidad de la reforma...», cit.), cuando sostiene que los recurrentes en inconstitucionalidad no acertaron al invocar el pluralismo político al que se refiere el art. 1.1. CE en apoyo de su defensa de la exigencia de mayorías reforzadas para la adopción de determinadas decisiones por el Consejo, y que debieran haber fundamentado el mismo en la propia Sentencia 108/1986 y lo sostenido allí por el Tribunal Constitucional.

56 Máxime si a lo anterior añadimos que el art. 600.4 LOPJ establece un quorum de constitución del Pleno de once miembros: diez vocales más el Presidente; regla que EnRIQue LuCAs Murillo ( «La mayoría simple en la adopción de los acuerdos del Consejo General del Poder Judicial», Revista de Derecho, Empresa y Sociedad, núm. 4, 2014), interpreta de forma rígida, partiendo de que la mayoría simple se computa conforme a un criterio subjetivo de mayoría simple de los presentes, de modo que para que dicha mayoría concurra no sería suficiente con que una propuesta sea la más votada, sino que esa propuesta supere el umbral señalado de la mitad más uno de los miembros presentes.

${ }_{57}$ En el mismo sentido LuCAs Murillo («La mayoría simple...», cit.,) defiende el establecimiento de mayorías reforzadas en estos supuestos, o al menos, la exigencia de mayoría absoluta en asuntos de especial trascendencia. Posición similar mantiene Martínez Alarcón («El Tribunal Constitucional avala la constitucionalidad de la reforma...», cit.), afirmando que "aunque es cierto que la regla de los tres quintos puede traer consigo situaciones de bloqueo en la adopción de determinadas decisiones, en particular las relativas al nombramiento discrecional de altos cargos judiciales, también es verdad que su presencia permite garantizar una mayor pluralidad de sensibilidades que se consideran absolutamente necesaria, en particular, por lo que bace a la composición del Tribunal Supremo.» 
Disciplinaria, aspecto que ha negado, puesto que no hay nada previsto al efecto y no existe entre la Comisión Disciplinaria y el Pleno una relación de subordinación jerárquica, concluyendo que, pese a su denominación legal, no se trata de un recurso de alzada en sentido propio ${ }^{58}$. No obstante, esta decisión dista de ser pacífica, tal y como muestra el voto particular suscrito por cinco magistrados en esta misma sentencia en el que se sostiene: «por más que se le califique de «impropio» lo cierto es que concurren en él las notas que caracterizan el recurso de alzada (...). Está en la propia naturaleza y esencia del recurso de alzada el que éste deba ser resuelto por u órgano distinto al que dictó la resolución impugnada; y también el que, tratándose de órganos colegiados, no formen parte del segundo las personas que ya bubiesen dictado el acto impugnado en alzada», y por tanto entienden que «quienes han intervenido directamente en la decisión no pueden participar en la resolución del recurso de alzada dirigido contra ella» ${ }^{59}$.

Por lo que se refiere al control jurisdiccional de los acuerdos del Pleno, la regulación incorporada con la LO 4/2013 crea una nueva sección en la Sala de la Contencioso-Administrativo para conocer de los acuerdos del Pleno y la Comisión Permanente del CGPJ que pongan fin a la vía administrativa, sección que estará integrada por «el Presidente de la Sala de lo Contencioso-Administrativo del Tribunal Supremo, que la presidirá, y por los demás Presidentes de sección de dicha Sala» (art. 638.2 LOPJ).

Esta previsión no obsta, según ha manifestado el Tribunal Supremo, para que, si se dan las circunstancias previstas en el artículo 197 LOPJ, puedan conocer del asunto todos los magistrados de la Sala ${ }^{60}$.

\section{Atribuciones del Consejo General del Poder Judicial}

En el ámbito de las competencias atribuidas al Consejo, las verdaderas novedades de la reforma se concentran en la regulación de la extensión de la potestad reglamentaria del órgano. De forma sintética, y sin que la Exposición de Motivos explique las razones de esta modificación, salvo para indicar que "debe referirse, con carácter general, a la esfera puramente interna o doméstica", pero que "excepcionalmente, se reconoce una potestad reglamentaria ad extra, en determinados aspectos accesorios de las actuaciones judiciales que se prevén en esta Ley Orgánica», la reforma de 2013 vuelve a la situación anterior a la prevista en la reforma legislativa de 1994, y reduce el ámbito de materias que el antiguo art. 110 LOPJ atribuía al Consejo.

58 Sentencia del Tribunal Supremo de 3 de marzo de 2014.

59 Voto particular a la sentencia del Tribunal Supremo de 3 de marzo de 2014. El Anteproyecto de Ley Orgánica del Poder Judicial, aprobado el 3 de abril de 2014 recoge la misma regulación a la aquí explicada. De hecho, ante el mantenimiento en el nuevo Anteproyecto de este recurso, el informe del CGPJ aconseja su eliminación, precisamente aludiendo a este voto particular (pp. 443-444, 458-459 y 505-506).

${ }^{60}$ Sentencia del Tribunal Supremo de 3 de marzo de 2014. En contra, un voto particular de esa misma sentencia, que entiende que la previsión específica del artículo 638 impide la aplicación del artículo 197 LOPJ. 
Las modificaciones en esta materia, como no podía ser de otro modo, han sido objeto de distintas valoraciones, si bien resultan bastante coincidentes en su juicio negativo, aunque desde perspectivas y alcanzando conclusiones dispares: unos por entender que supone un desapoderamiento injustificado del Consejo ${ }^{61}$, otros por considerar que el nuevo texto legal es muy similar al anterior, y que en definitiva nos deja donde estábamos ${ }^{62}$.

Con todo el texto finalmente aprobado se aleja del propuesto por la Comisión institucional, especialmente en lo que se refiere al listado de materias reservadas al Consejo (art. 560 LOPJ) ${ }^{63}$. Esquemáticamente las novedades principales de la reforma de 2013 en esta materia serían las siguientes:

i) En relación potestad doméstica o interna del CGPJ, es decir, las materias sobre las que el Consejo puede dictar normas reglamentarias mantiene el dictado de la propuesta de la Comisión institucional, incluyendo, por tanto, la organización y funcionamiento del CGPJ, el personal a su servicio en el marco de la función pública, Escuela Judicial y CENDOJ, órganos de gobierno de los juzgados y tribunales y publicación de resoluciones judiciales.

${ }^{61}$ Gerpe Landín y Cabellos Espiérrez: «La reforma permanente...», cit., págs. 35 y sigs. La reforma, según LuCAS MuRILlo DE la Cueva («La posición institucional del Consejo General del Poder Judicial y sus relaciones con los órganos constitucionales», cit., págs. 76-77), «descansa en la idea de que el Consejo General del Poder Judicial ha adquirido una dimensión excesiva, considera que se le han atribuido competencias que no se deberían habérsele atribuido», pero se trata de competencias que el Consejo ha extraído de la aplicación de la ley, que se mantenido con gobiernos de diferentes mayorías, y sin que el Tribunal Supremo haya anulado las normas reglamentarias del Consejo más que en un número reducido de ocasiones. Por tanto, considera la reforma legal desproporcionada y excesiva, en la medida en que no responde a un problema de ejercicio de esta potestad por el órgano de gobierno del Poder Judicial, sino a una intencionalidad de rebajar su posición. También se manifestó en contra el propio Consejo en su Informe al Anteproyecto de Ley Orgánica, que ya ha sido citado.

62 María Fraile Ortiz: «La «nueva» potestad reglamentaria del Consejo General del Poder Judicial en la Ley Oránica 4/2013: La reforma que no fue», en Luis AGuiAr De LuQue: «Independencia Judicial y Estado Constitucional. El gobierno judicial, Valencia, Tirant lo Blanch, 2016, pág. 163.

63 Este alejamiento del texto inicial propuesto por la mencionada Comisión, que sí hubiera supuesto una verdadera modificación y reducción sustancial de la potestad reglamentaria del Consejo, y que se realizó en gran medida por vía de enmienda en el Senado, recuperando cierta potestad reglamentaria instrumental sobre el régimen de la Carrera Judicial, puede deberse a un intento de salir al paso a algunas de las cuestiones que se abrían con la propuesta, como la competencia para completar por vía reglamentaria completar el estatuto judicial. En el mismo sentido, GerPe LANDín y CABELloS ESPIÉRREZ: «La reforma permanente...», cit., págs. 35 y sigs., y LuCAS Murillo de la Cueva: La posición institucional del Consejo General del Poder Judicial y sus relaciones con los órganos constitucionales», cit., págs. 77. Así también lo constató el Informe del Consejo a que se ha hecho referencia, y mostró su preocupación el Consejo Fiscal en su correspondiente Informe al mismo Anteproyecto aprobado en febrero de 2013. 
ii) Excluye la estadística judicial, que inicialmente estaba incluida en la propuesta inicial ${ }^{64}$.

iii) Incorpora el régimen de guardias de los órganos judiciales, que ya constaba en la reforma de 1994, y se reintroducen las materias que el antiguo art. 110 LOPJ recogía tras la reforma efectuada por la Ley Orgánica 16/1994.

iv) Mantiene la potestad reglamentaria del Consejo en lo relativo a la cooperación jurisdiccional, si bien limitada a la «organización y gestión de la actuación de los órganos judiciales españoles» en la materia; precisión que resulta lógica toda vez que esta regulación ha de ser compatible con la normativa europea en la materia y la que se establezca en otros Tratados y Acuerdos internacionales.

v) Como materias nuevas introduce la potestad reglamentaria en materia de reutilización de resoluciones judiciales, que ha de interpretarse conforme a la Sentencia del Tribunal Supremo de 28 de diciembre de 2011, que anuló el Reglamento 3/2010 del CGPJ, en el sentido de que no le corresponde al Consejo regular el mercado de la reutilización. También incorpora la materia relativa al establecimiento de las bases y estándares de compatibilidad de los sistemas informáticos que se utilicen en la Administración de Justicia, y la relativa al régimen jurídico de las Asociaciones judiciales.

vi) En relación con el estatuto de jueces y magistrados, la potestad reglamentaria, siguiendo la terminología introducida por la Ley Orgánica 16/1994, no podrá suponer innovación o alteración de la regulación legal.

vii) Excluye toda potestad reglamentaria ad extra del Consejo, impidiendo que el ejercicio de esta potestad pueda no ya referirse a derechos y deberes de personas ajenas al CGPJ, sino siquiera afectar a los mismos. El legislador se aleja de la línea inaugurada con la reforma de 1994, y posteriormente reforzada por la Ley de modi-

${ }^{64}$ No obstante, lo cierto es que el legislador nunca ha parecido tener muy claro si esta competencia debe corresponder al Consejo. Es indudable que se trata de un instrumento fundamental para el ejercicio del Consejo de sus competencias (en concreto en el ejercicio de la función inspectora), pero también para el diseño de políticas públicas que compete realizar al Ministerio de Justicia. No parece, pues, descabellado entender que la función de recopilación y ordenación de datos estadísticos (no olvidemos que la esta función se ejerce por los Letrados de la Administración de Justicia a quienes la LOPJ atribuye la confección de la Estadística Judicial), pueda estar en manos ministeriales, pues conocer los datos no necesariamente implica tener su titularidad y gestión, sin perjuicio del mantenimiento del Comité de Estadística Judicial, como órgano tripartito en el que CGPJ, Ministerio de Justicia y Comunidades Autónomas están representadas. Así también lo entiende DAVID Giménez GLuCK: «Las funciones del órgano de gobierno del Poder Judicial no directamente atribuidas por la Constitución», en Luis Aguiar de Luque: «Independencia Judicial y Estado Constitucional. El gobierno judicial, Valencia, Tirant lo Blanch, 2016, págs. 175-177. 
ficación 19/2003; lo que puede deberse, porque no se explica en la Exposición de Motivos, ni en la Memoria de Impacto Normativo que acompañaba al Anteproyecto, a lo sostenido por el Tribunal Supremo en la Sentencia de 2011 antes citada.

Por su parte, la Disposición Adicional 1. ${ }^{a}$ de la LO 4/2013 dispone que los reglamentos actuales aprobados por el CGPJ «conservarán su vigencia, en tanto sean compatibles con la presente ley orgánica», de forma que el Consejo deberá ir valorando qué reglamentos, o parte de los mismos, son aplicables por ser acordes con la nueva Ley Orgánica, y cuales no por contravenir ésta, planteándose a partir de ahí la duda de a quién corresponde completar la laguna que se produzca. ${ }^{65}$

Pero las reformas en el ámbito competencial no se han limitado a la potestad reglamentaria del CGPJ. También han alcanzado a otras facetas de la actuación del Consejo. Una de ellas, que levantó ampollas en el propio Consejo, como recoge su Informe al Anteproyecto, se refiere a la actividad internacional del CGPJ. Según el nuevo art. 562 LOPJ, las actividades internacionales del CGPJ se llevarán a cabo "en coordinación con el Ministerio de Asuntos Exteriores y de acuerdo con las directrices en materia de política exterior que, en el ejercicio de sus competencias, sean fijadas por este, sin perjuicio de las competencias que en materia de cooperación jurisdiccional internacional ostenta el Consejo General del Poder Judicial de acuerdo con lo dispuesto en la presente Ley Orgánica».

Pese a las críticas suscitadas en el seno del Consejo, lo cierto es que la doctrina ya había alertado de la desmedida actividad del Consejo que ha alcanzado materias y asuntos que trascienden las que son propias de su función constitucional ${ }^{66}$. Por tanto, en esa medida limitar la actuación internacional del Consejo no es necesariamente rebajar su posición institucional sino ajustarla a sus términos constitucionales. De hecho, no parece discutible la necesidad de coordinación entre CGPJ y Ministerio, pues, al fin y al cabo las relaciones internacionales y la dirección de la política internacional son competencia del Gobierno y, dentro del mismo, del Ministerio de Asuntos Exteriores, por lo que la referencia a que el Consejo actúe siguiendo las directrices que fije el ejecutivo no puede valorarse más que como un reflejo de la función gubernamental de dirección política atribuida en el art. 97 CE al Gobierno.

En lógica correspondencia se exceptúa el ámbito de la cooperación jurisdiccional internacional, que, sin duda, no hubiera podido someterse a ese régimen de dependencia, y que es aplicación de la legislación vigente en la materia, como es la Ley

${ }^{65}$ Solución que no otorga una clara seguridad jurídica, En este sentido, Rosa MARÍA: «¿Regeneración democrática? Algunas reflexiones sobre la nueva Ley Orgánica 4/2013, de 28 de junio, de reforma del Consejo General del Poder Judicial», Revista de Derecho Político, núm. 91, 2014, pág. 151.

66 Rosa Velázquez Álvarez: «La extravagancia internacional del Consejo General del Poder Judicial», en Revenga Sánchez, M., El Poder Judicial, Valencia, Tirant lo Blanch, Valencia, 2009, págs. 295 y sigs. Asimismo, Diego Í̃̃IgueZ HernÁndeZ ( «Las funciones ad extra del CGPJ», en LuIs Aguiar De LuQue (coord.): El gobierno del poder judicial. Una perspectiva comparada. Centro de Estudios Políticos y Constitucionales, Madrid, 2012, págs. 97 y sigs.), aboga por limitarla más, ciñéndola exclusivamente a colaboraciones técnicas o instrumentales con el Gobierno. 
29/2015, de 30 de julio, de cooperación jurídica internacional en materia civil, o la Ley Orgánica 7/2014, de 12 de noviembre, de intercambio de información de antecedentes penales y de consideración de resoluciones judiciales penales en la Unión Europea, de la normativa europea y de los Tratados y Acuerdos internacionales válidamente ratificados por España.

El art. 560.1.19. ${ }^{a}$ LOPJ añade una nueva atribución del Consejo, a saber, colaborar con la Autoridad de Control en materia de protección de datos en el ámbito de la Administración de Justicia, y asumir las competencias como Autoridad de Control respecto a la utilización de los ficheros judiciales. La inclusión de esta nueva competencia responde a lo resuelto por el Tribunal Supremo en su Sentencia de 2 de diciembre de 2011, en la que negó que la Agencia Española de Protección de Datos pudiera ejercer sus funciones de control y tutelares en relación con los Juzgados y Tribunales, habida cuenta de que la inspección de los mismos es competencia exclusiva del CGPJ.

Pese a lo dicho por el Tribunal Supremo y a lo previsto en el citado precepto, la Ley, aunque sí incluye una regulación respecto al régimen de acceso, y responsabilidad de los datos obrantes en los ficheros judiciales, no recoge ninguna previsión en punto a cómo debe ejercerse esta función, ni a quién corresponde su ejercicio, si bien es posible inferir del texto de la Ley que, en tanto no atribuida expresamente a ningún órgano de la estructura interna del Consejo, las decisiones sobre esta materia deberán corresponder a la Comisión permanente.

Por supuesto que ha habido otras modificaciones en el ámbito competencial del Consejo, pero entiendo que las expuestas son las más relevantes y significativas. No obstante, y pese a que un análisis más pormenorizado excedería sobradamente los límites de este trabajo, sí quisiera dejar constancia de una conclusión ya adelantada en alguna medida: si bien la Ley Orgánica 4/2013 puede considerase como un intento de racionalizar las funciones del Consejo, ha resultado insuficiente, pocas cosas han cambiado, pese a las modificaciones habidas en la estructura orgánica y en el estatuto de los vocales. La existencia de profundos cambios en un lado de la ecuación, que no se reflejan en el otro, tiene como consecuencia un desajuste que probablemente derive en la incapacidad del órgano de gobierno para seguir afrontando el ejercicio regular de sus competencias (como pone ya de relieve que dos años después de la reforma de 2013 hubiera de modificarse la LOPJ en 2015 para ampliar el número de miembros de la Comisión permanente).

Si esto es así, la próxima reforma, en caso de existir, debiera replantearse el ámbito competencial del Consejo, y ajustar aquellas funciones que no constituyen el núcleo constitucionalmente atribuido de forma que complementen mejor a las atribuciones que el constituyente reservó al Consejo, y prescindir o al menos restringir las que alejen al CGPJ de sus cometidos constitucionales ${ }^{67}$.

${ }^{67}$ En el mismo sentido, Giménez GLuCK: «Las funciones del órgano de gobierno del Poder Judicial....», cit., pág. 193. 


\section{Relaciones entre el Consejo General del Poder Judicial y las Cortes Generales: las comparecencias del Presidente y de los vocales ante las Cámaras parlamentarias}

Al margen de la participación de las Cámaras parlamentarias en la designación de los miembros del CGPJ, el art. 563 LOPJ impone al Consejo la obligación de remitir anualmente a las Cortes Generales una Memoria «sobre el estado, funcionamiento y actividades del propio Consejo General del Poder Judicial y de los Juzgados y Tribunales, donde se incluirán las necesidades que, a su juicio, existan en materia de personal, instalaciones y recursos para el correcto desempeño de las funciones que la Constitución y las leyes asignan al poder judicial», que además incluirá un capítulo dedicado al impacto de género en el ámbito judicial. Las Cortes podrán, de acuerdo a los Reglamentos de las Cámaras debatir el contenido de la Memoria y solicitar la comparecencia del Presidente del Tribunal Supremo, para que responda a las preguntas que se planteen acerca de dicha Memoria.

Aunque no se trata de una fórmula de control parlamentario en sentido estricto, o propio ${ }^{68}$, es una especificación del deber genérico de información a las Cámaras que prevé el art. 109 CE y que se refiere a cualquier autoridad del Estado. Pero es también una oportunidad, de hecho, la única, para que los parlamentarios puedan dirigir pregunta al Presidente del Consejo, toda vez que el art. 564 LOPJ establece que « $(f)$ uera del supuesto previsto en el artículo anterior, sobre el Presidente del Tribunal Supremo y los Vocales del Consejo General del Poder Judicial no recaerá deber alguno de comparecer ante las Cámaras por razón de sus funciones».

Esta previsión, que pretende dar respuesta a la polémica acontecida con motivo de la negativa de algún Presidente del Consejo a comparecer (concretamente la que se produjo en 2006, el 15 de marzo, cuando el entonces Presidente del CGPJ, Francisco Hernando, se negó a comparecer en la Comisión de Justicia del Congreso), y la generada por la propuesta de introducir un deber de comparecencia del Presidente y los vocales a petición de los parlamentarios, ha sido uno de los preceptos frente a los que se dirigió el recurso de inconstitucionalidad promovido por el Grupo Socialista del Congreso contra la Ley Orgánica 4/2013, por considerar que el precepto legal impugnado desconoce: la reserva en favor de los reglamentos que establecería el art. 72.1 CE; la obligación de comparecer ante las Comisiones de investigación prevista en el art. 76 CE; la facultad de las Cámaras y sus Comisiones de requerir información y ayuda de cualquier autoridad del Estado, y el principio democrático contemplado en el art. 1 CE y el principio de separación de poderes, por no establecer un sistema de responsabilidad política

68 En el mismo sentido, DAvid Giménez GLUCK: «La comparecencia de los miembros del CGPJ ante las Cortes Generales: una reflexión constitucional», Revista Española de Derecho Constitucional, núm. 87, 2009, págs. 217-219. De forma distinta Í̃̃IGUEZ HERNÁNDEZ ( «as funciones ad extra del CGPJ», cit., págs. 107-108), considera que se trata de una forma peculiar de control "tanto por el alcance de su objeto como por la posibilidad de que el compareciente se convierta, a su vez, en reclamante.» 
del Poder Judicial, que debiera conducir, a su parecer, en el deber de todos los miembros del Consejo, Presidente y vocales, de comparecer ante las Comisiones de Justicia.

La Sentencia 191/2016, tras un examen más detallado y pormenorizado al que el que dedica a otras cuestiones planteadas en el recurso, probablemente de mayor trascendencia y con consecuencias más profundas en la posición y el funcionamiento del órgano de gobierno del Poder Judicial, declara la constitucionalidad del precepto y sostiene que, dada la posición institucional del Consejo respecto al resto de poderes públicos, la Constitución «descarta, sin sombra de duda, semejantes pretensiones de «responsabilidad» $y$ «control» políticos sobre un órgano constitucional al que ba confiado, en garantía de la independencia de jueces y magistrados, unas funciones que no pueden quedar, sin amenaza o daño para esa independencia, sujetas a fiscalización por el poder político, incluido, claro está, el que se expresa en las Cámaras representativas» ${ }^{69}$.

Ello no impide que el Consejo quede concernido por lo previsto en los arts. 76 y art. 109 CE. De modo que el art. 564 LOPJ no contradice el deber de comparecencia ante las comisiones de investigación parlamentarias, siempre que se interprete que el art. 564 LOPJ, desplegará su eficacia en el ámbito de las relaciones ordinarias entre las Cortes Generales y el Consejo, pero que la comparecencia ante las comisiones de investigación encuentra su marco de referencia en el control extraordinario ocasional que desarrollan las Cortes y que el art. 564 LOJ no se refiere al mismo, no afectando, en suma, al deber de comparecer de los miembros del Consejo ante las comisiones de investigación.

Tampoco impide, el art, 564 LOPJ, que el Consejo, como el resto de autoridades públicas, pueda prestar información y ayuda a las Cámaras, siempre que esa solicitud se corresponda con el ámbito funcional del Consejo y no menoscabe el ejercicio independiente de sus competencias. Sin embargo, ese requerimiento constitucional y el deber que nace del mismo no tienen más recorrido, en la medida en que la norma no establece el modo, ni los procedimientos a través de los que debe realizarse, ni prescribe que dicha asistencia deba producirse mediante la comparecencia parlamentaria de las autoridades a que se refiere, comparecencia que sí se contempla en el art. 110.1 CE, respecto a los miembros del Gobierno.

En consecuencia, la asistencia y ayuda que las Cámaras puedan demandar puede practicarse de diversos modos, que no quedan previstos constitucionalmente, aunque sí deriva del texto constitucional, dice el Tribunal, de forma clara que la comparecencia del Presidente sólo puede preverse, en su caso, en la Ley Orgánica a que se refiere el art. 122.2 CE.

Consecuentemente, concluye el Tribunal que el art. 563.3 de la LOPJ, fruto de la libertad de configuración del legislador, prevé una forma de dar cauce a lo pre-

69 Fundamento jurídico 6. 
visto en el art. $109 \mathrm{CE}$, que no excluye otros cauces de información y ayuda a las Cámaras, que no sean la comparecencia del Presidente y los vocales, como la información por escrito, o eventualmente, la presencia, cuando proceda, de altos funcionarios del Consejo ${ }^{70}$, y añade que el art. 561.1 LOPJ, regla 9, dispone que se someterá a informe del CGPJ cualquier otra cuestión que las Cortes Generales consideren oportuna, previsión que se incardina en la función consultiva del Consejo, pero que "habilita en muy amplios términos un nuevo cauce para la colaboración, cuando proceda, entre el Consejo mismo y las Cámaras», colaboración que, al entender del Tribunal, también sirve en términos generales al efecto de lo contemplado en el art. 109 CE.

Admitiendo lo dicho por el Tribunal, desde una perspectiva distinta, que es, por supuesto, ajena al juicio de constitucionalidad, parece aconsejable arbitrar en la LOPJ instrumentos y cauces de colaboración e información parlamentaria de la labor que realiza el Consejo, y las comparecencias del Presidente y de los miembros del Consejo puede ser un medio adecuado para ello, sin perjuicio de que se arbitren fórmulas que impidan un uso desproporcionado o desleal del mecanismo concreto $^{71}$.

\section{CONSIDERACIONES FINALES}

Si la Ley Orgánica 4/2013 pretendía ajustar el modelo de CGPJ a sus dictados constitucionales, reduciendo la complejidad de su organización, y adecuando sus funciones al elenco competencial atribuido constitucionalmente al órgano de gobierno del Poder Judicial, la primera conclusión, sin perjuicio de que algunos aspectos merezcan una valoración positiva, no puede ser más desalentadora ${ }^{72}$.

El texto finalmente aprobado por las Cámaras, rechazado por todos los grupos de la oposición, se aleja notoriamente del presentado como propuesta por la Comisión institucional constituida al efecto. Es cierto que mantiene alguno de sus planteamientos, pero lo hace de forma acrítica y asistemática, de forma que

70 Fundamento jurídico 6.

71 En el mismo sentido, Martínez Alarcón: «El Tribunal Constitucional avala la constitucionalidad de la reforma....», cit., págs. 11-12, y GiMÉNEZ GLUCK: «La comparecencia de los miembros del CGPJ...», cit., pág. 219, y del mismo autor «Las funciones del órgano de gobierno del Poder Judicial...», cit., pág. 181 .

72 No sólo no se ha resuelto gran cosa, sino que determinadas modificaciones han planteado nuevos problemas, sin olvidar que la falta de una explicación y justificación razonada de la oportunidad de la Ley, permite albergar dudas sobre sus verdaderos fines, y sospechar, como la mayoría de la doctrina ha puesto de manifiesto, que parece nacer más del deseo de revancha contra un Consejo que en su composición anterior a la reforma (y al actual designado a finales de 2013 tras la renovación conforme al nuevo sistema) se había mostrado díscolo y abiertamente crítico con las propuestas normativas del Gobierno, y había dado pie a numerosos escándalos en la gestión del gasto como aireó la prensa. 
lo que era una medida justificada en la propuesta de la Comisión, plantea dudas en la Ley aprobada: como muestra la falta de sintonía entre la configuración de la Comisión permanente como órgano estructural básico y decisor del Consejo, cuyos miembros son los únicos que gozan de un régimen de dedicación exclusiva, para potenciar la agilidad y eficacia del funcionamiento y la no reducción efectiva de las competencias atribuidas al Consejo (el CGPJ sigue siendo una gran maquinaria que asume y ejerce funciones, previstas legalmente, sin duda, pero que exceden con mucho las que le son propias, y que, sin embargo, no ha resultado muy eficaz como órgano de garantía de la independencia judicial, fin para el que fue concebido $)^{73}$.

De otro lado, la práctica de este primer Consejo, conformado conforme a la Ley Orgánica 4/2013, pone de manifiesto que las viejas costumbres se mantienen: la división en bloques sigue existiendo, y el voto según los dictados del grupo con el que se identifica a cada vocal también, salvo alguna excepciones que, por demás, también se han dado en Consejos anteriores. A lo anterior hay que sumar las continuas tensiones generadas por la diferente situación administrativa de los vocales.

El Consejo actual no es, pues, más independiente. Antes bien, existe en el mismo una gran concentración de poder en manos de la Comisión permanente y del Presidente ${ }^{74}$ que gran parte de la doctrina valora negativamente por cuanto tiene de merma de la posición institucional del Consejo en relación con el ejecutivo, pero que, sin duda, incrementa notablemente las posibilidades de que la mayoría del CGPJ actúe al margen de la opinión de la minoría, por amplia que ésta sea. De ahí que la reforma en el régimen de mayorías para la adopción de acuerdos puede no ser inconstitucional, pero sin duda afecta a la pluralidad y al valor del pluralismo al que el Tribunal Constitucional se refirió en la Sentencia 108/1986.

Pero la Ley tampoco aborda todas las cuestiones pendientes. La adaptación al modelo territorial sigue sin abordarse, por ejemplo.

En resumen, probablemente hubiera sido más adecuado reformar la Constitución para reducir el número de miembros del Congreso y diseñar en aspectos más concretos el órgano de gobierno, y no contemplar una remisión al legislador tan general que deja en manos de la mayoría parlamentaria la configuración de un órgano constitucional en todos los aspectos, salvo el del número de miembros, las condiciones para su elegibilidad y la participación parlamentaria en la elección de sus miembros, o bien arriesgar en una reforma profunda del CGPJ en el margen amplio que la Constitución reconoce al legislador. Por el contrario, se ha optado por una reforma legal que no

${ }^{73}$ En la medida en que el Pleno y resto de las Comisiones sólo pueden ejercer las atribuciones especificadas legalmente, el peso fundamental de la actividad y funcionamiento de la institución descansa sobre la Comisión permanente, que ya ha visto ampliado el número de sus miembros dada la imposibilidad de realizar en condiciones todas las funciones encomendadas.

${ }^{74}$ Como presidencialista califica Í̃̃IgUEZ HeRnÁNDEZ («Contrarreforma.....», cit., pág. 342) el modelo auspiciado por la Ley Orgánica 4/2013. 
afronta los problemas del Consejo, minora su posición, no favorece su independencia, ni evita la politización, probablemente porque, pese a los recursos a la independencia del Consejo que jalonan sus declaraciones públicas, los responsables políticos no estén dispuestos a una reforma que les impida el acceso y la influencia en el órgano de gobierno del Poder Judicial. En definitiva, la Ley Orgánica 4/2013, «resultó finalmente una nueva ocasión frustrada para establecer el régimen jurídico del órgano de gobierno del Poder Judicial acorde con la misión constitucional para la que fue concebido por el constituyente de 1978... Otra vez será» ${ }^{75}$.

Title:

The reception of the Judiciary government in the Spanish Constitution: forty years about the General Council of the Judiciary

\section{Summary:}

I. The reception of the Judiciary government in the Spanish Constitution: forty years about the General Council of the Judiciary.II. Regulation present and open questions. 1. About the Organic Law 4/2013, for reforming the CGPJ. 2. Elections system, status of its members and restaffinf of the organ.3. Organic Structure of the General Council of the Judiciary and questions about the functioning of its organs.4. Powers of the General Council of the Judiciary. 5. Relationship between the General Council of the Judiciary and the Spanish Parlament: the Appearance of the President anf the members of Council before the House of Representatives.III. Ultimate considerations.

\section{Resumen:}

La Constitución española de 1978 consagró el Consejo General del Poder Judicial, como órgano de gobierno del Poder Judicial. Desde su creación en 1980, este órgano ha estado sometido a constantes reformas, en un proceso de continuas modificaciones que han derivado en un órgano que no parece haber encontrado su lugar en el sistema institucional, y no ha podido consolidarse. La última reforma más importante, la Ley Orgánica 4/2013, de reforma del CGPJ, ha introducido una nueva reformulación del modo de elección, la estructura y las funciones del CGPJ. El presente

75 Luis Aguiar de Luque: «Continuidad y reforma en el Régimen Jurídico del Consejo General del Poder Judicial», cit., pág. 26. 
trabajo expone la evolución y los cambios habidos en el Consejo en estos cuarenta años de vigencia constitucional, y analiza el régimen establecido por la reforma de 2013, la nueva posición del Consejo y de sus órganos de funcionamiento, la dudas sobre el funcionamiento que plantea y las cuestiones que aún siguen abiertas.

\begin{abstract}
:
The Spanish Constitution of 1978 established the General Council of the Judiciary, as an organ for the Judiciary government. Since of its creaction on 1980,this organ has been objet of a constant process of reforming that shows how the Conuncil hasn't achieved to find its place in institutional system and how this organ couldn't consolidate itself under a stable model. The last most important reform, the Organic Law 4/2013, reforming the CGPJ, has introduced in a reformulation of the structure and functions of the Council, and a new way of election of its members, thus constituting. This paper presents the evolution and the changes about of Council in forty years of constitutional vigence and analyzes the reform, the new position and place of Council and its organs, the doubts on the functioning of the Council, and the questions that today remain open.
\end{abstract}

\title{
Palabras clave:
}

Poder judicial. Gobierno del Poder Judicial. Consejo General del Poder Judicial. Independencia judicial. Regulación constitucional y legal del poder judicial. Separación de poderes.

Key words:

Judicial power. Judiciary government. Judicial Council. General Council of the Judiciary; Judicial Independence. Guaranties of Independence. Constitutional and legal regulation; Separation of powers. Division of powers. 